\title{
Secondary cyclogenesis along an occluded front leading to damaging wind gusts: windstorm Kyrill, January 2007
}

Article

Published Version

Ludwig, P., Pinto, J. G., Hoepp, S. A., Fink, A. H. and Gray, S. L. (2015) Secondary cyclogenesis along an occluded front leading to damaging wind gusts: windstorm Kyrill, January 2007. Monthly Weather Review, 143 (4). pp. 1417-1437. ISSN 0027-0644 doi: https://doi.org/10.1175/MWR-D-14-00304.1 Available at https://centaur.reading.ac.uk/38665/

It is advisable to refer to the publisher's version if you intend to cite from the work. See Guidance on citing.

Published version at: http://dx.doi.org/10.1175/MWR-D-14-00304.1

To link to this article DOI: http://dx.doi.org/10.1175/MWR-D-14-00304.1

Publisher: American Meteorological Society

All outputs in CentAUR are protected by Intellectual Property Rights law, including copyright law. Copyright and IPR is retained by the creators or other copyright holders. Terms and conditions for use of this material are defined in the End User Agreement.

www.reading.ac.uk/centaur 
Central Archive at the University of Reading

Reading's research outputs online 


\title{
Secondary Cyclogenesis along an Occluded Front Leading to Damaging Wind Gusts: Windstorm Kyrill, January 2007
}

\author{
PATRICK LUDWIG \\ Institute for Geophysics and Meteorology, University of Cologne, Cologne, Germany \\ JOAQUIM G. PINTO \\ Department of Meteorology, University of Reading, Reading, United Kingdom, and Institute for \\ Geophysics and Meteorology, University of Cologne, Cologne, Germany \\ SIMONA A. HOEPP \\ Institute for Geophysics and Meteorology, University of Cologne, Cologne, Germany \\ ANDREAS H. FINK \\ Institute for Meteorology and Climate Research, Karlsruhe Institute of Technology, \\ Karlsruhe, Germany \\ SUZANNE L. GRAY \\ Department of Meteorology, University of Reading, Reading, United Kingdom
}

(Manuscript received 23 September 2014, in final form 19 November 2014)

\begin{abstract}
Windstorm Kyrill affected large parts of Europe in January 2007 and caused widespread havoc and loss of life. In this study the formation of a secondary cyclone, Kyrill II, along the occluded front of the mature cyclone Kyrill and the occurrence of severe wind gusts as Kyrill II passed over Germany are investigated with the help of high-resolution regional climate model simulations. Kyrill underwent an explosive cyclogenesis south of Greenland as the storm crossed poleward of an intense upper-level jet stream. Later in its life cycle secondary cyclogenesis occurred just west of the British Isles. The formation of Kyrill II along the occluded front was associated (i) with frontolytic strain and (ii) with strong diabatic heating in combination with a developing upper-level shortwave trough. Sensitivity studies with reduced latent heat release feature a similar development but a weaker secondary cyclone, revealing the importance of diabatic processes during the formation of Kyrill II. Kyrill II moved farther toward Europe and its development was favored by a split jet structure aloft, which maintained the cyclone's exceptionally deep core pressure (below $965 \mathrm{hPa}$ ) for at least $36 \mathrm{~h}$. The occurrence of hurricane-force winds related to the strong cold front over north and central Germany is analyzed using convection-permitting simulations. The lower troposphere exhibits conditional instability, a turbulent flow, and evaporative cooling. Simulation at high spatiotemporal resolution suggests that the downward mixing of high momentum (the wind speed at $875 \mathrm{hPa}$ widely exceeded $45 \mathrm{~m} \mathrm{~s}^{-1}$ ) accounts for widespread severe surface wind gusts, which is in agreement with observed widespread losses.
\end{abstract}

Corresponding author address: Patrick Ludwig, Institute for Geophysics and Meteorology, University of Cologne, Pohligstr. 3, 50969 Cologne, Germany.

E-mail: pludwig@meteo.uni-koeln.de

DOI: 10.1175/MWR-D-14-00304.1 


\section{Introduction}

In January 2007, windstorm Kyrill ${ }^{1}$ (cf. Fink et al. 2009) swept across large parts of western, central, and eastern Europe resulting in 54 fatalities and overall insured losses of 4.6 billion Euro (EUR) in Germany, the United Kingdom, Belgium, and the Netherlands (economic losses even reached 7.6 billion EUR; Swiss Re 2008). As described in Fink et al. (2009) Kyrill underwent explosive cyclogenesis [a pressure drop of more than $24 \mathrm{hPa}$ in $24 \mathrm{~h}$ at $60^{\circ} \mathrm{N}$, cf. Sanders and Gyakum (1980)] over the northeastern Atlantic between 1200 UTC 16 January (998 hPa) and 1200 UTC 17 January $(968 \mathrm{hPa})$. Most of the extratropical systems affecting Europe originate and intensify in this region, known as the North Atlantic storm track (e.g., Hoskins and Valdes 1990). Like Kyrill, most of those systems emerged in a baroclinic environment (Hoskins and Hodges 2002; Wernli et al. 2002; Gray and Dacre 2006), which is associated with a strong upper-tropospheric jet stream (Carlson 1991). During the period of explosive cyclogenesis, Kyrill crossed the jet stream from the warm to the cold side (Fink et al. 2009, see their Fig. 1). The crossing of the jet stream is known to correspond with the rapid deepening phase of extratropical cyclones (e.g., Palmen and Newton 1969). Thus, upper-level divergence at the right entrance and left exit region of the jet streak (region of wind maximum within the jet stream) played a crucial role in enhancing the cyclone evolution (Uccellini and Johnson 1979).

Fink et al. (2009) speculated that Kyrill would have then slowed down and decayed over the North Atlantic under normal circumstances. However, at 0000 UTC 18 January a secondary cyclogenesis initiated along the occluded front of Kyrill (hereafter Kyrill I), forming a secondary cyclone (hereafter Kyrill II), which then moved farther toward Europe (Fig. 1). In general, secondary cyclones are formed from frontal waves along synoptic fronts (e.g., the trailing cold front of a parent low; Parker 1998a). Relative to the climatological storm track location, the preferred area for these events is shifted downstream and slightly south (Ayrault et al. 1995). Such systems often reach Europe, typically during zonal weather regimes.

Zonal weather regimes over the North Atlantic are characterized by westerly flows and are associated with

\footnotetext{
${ }^{1}$ Storm names employed herein are as given by the Freie Universität Berlin and as used by the German Weather Service. (Source: http://www.met.fu-berlin.de/adopt-a-vortex/archiv/.)
}

slightly to moderately positive values of the North Atlantic Oscillation (NAO; e.g., Wanner et al. 2001) index. In January 2007, the NAO index ${ }^{2}$ was strongly positive $(+1.77)$ resulting in a series of extratropical cyclones (Anton, 3 January; Franz, 11 January; Gerhard, 13 January; Hanno, 14 January; Lancelot, 20 January) over the North Atlantic with Kyrill being the most intense in terms of maximum wind gusts and precipitation amounts over central Europe. This successive occurrence of cyclones (building a cyclone family) is also known as serial clustering (Mailier et al. 2006; Pinto et al. 2013). Additionally, the NAO dipole was shifted toward Europe forming an enhanced background pressure gradient (associated with amplified wind speeds at the surface) between western Europe and the Baltic states, in which the cyclones were embedded (Fink et al. 2009, see their Fig. 2).

The dynamics of such secondary cyclones have been investigated in several studies using either reanalysis data (e.g., Rivals et al. 1998; Chaboureau and Thorpe 1999) or numerical models (Carrera et al. 1999). A comprehensive review of the dynamics of frontal waves and secondary cyclones is given by Parker (1998a). Therein, the shear at the frontal zone, the weakening of large-scale strain (or stretching deformation) field in the environment of the front, diabatic heating effects due to latent heat release inside clouds, boundary layer processes, and the influence of a local strip of maximum potential vorticity (PV) are mentioned as decisive mechanisms for secondary cyclogenesis. Several studies investigated the influence of the environmental deformation field on frontal wave development. An idealized study by Dritschel et al. (1991) provided evidence that deformation primarily affects the growth of an edge wave. Several following studies (e.g., Bishop and Thorpe 1994a,b; Renfrew et al. 1997; Parker 1998b; Dacre and Gray 2006) further documented the importance of deformation strain on frontal wave development. While frontal wave development is suppressed in case of sufficient positive (frontogenetic) stretching deformation, reduced or negative (frontolytic) strain favors the occurrence of barotropic instabilities and thus of frontal wave development.

Intensive convection with severe wind gusts and exceptional precipitation amounts (some of them exceeding the mean January accumulations) were observed as the cold front passed over central Europe.

\footnotetext{
${ }^{2}$ A continuous update of the NAO index on monthly and seasonal scales is available at http://www.cru.uea.ac.uk/ timo/ datapages/naoi.htm.
} 


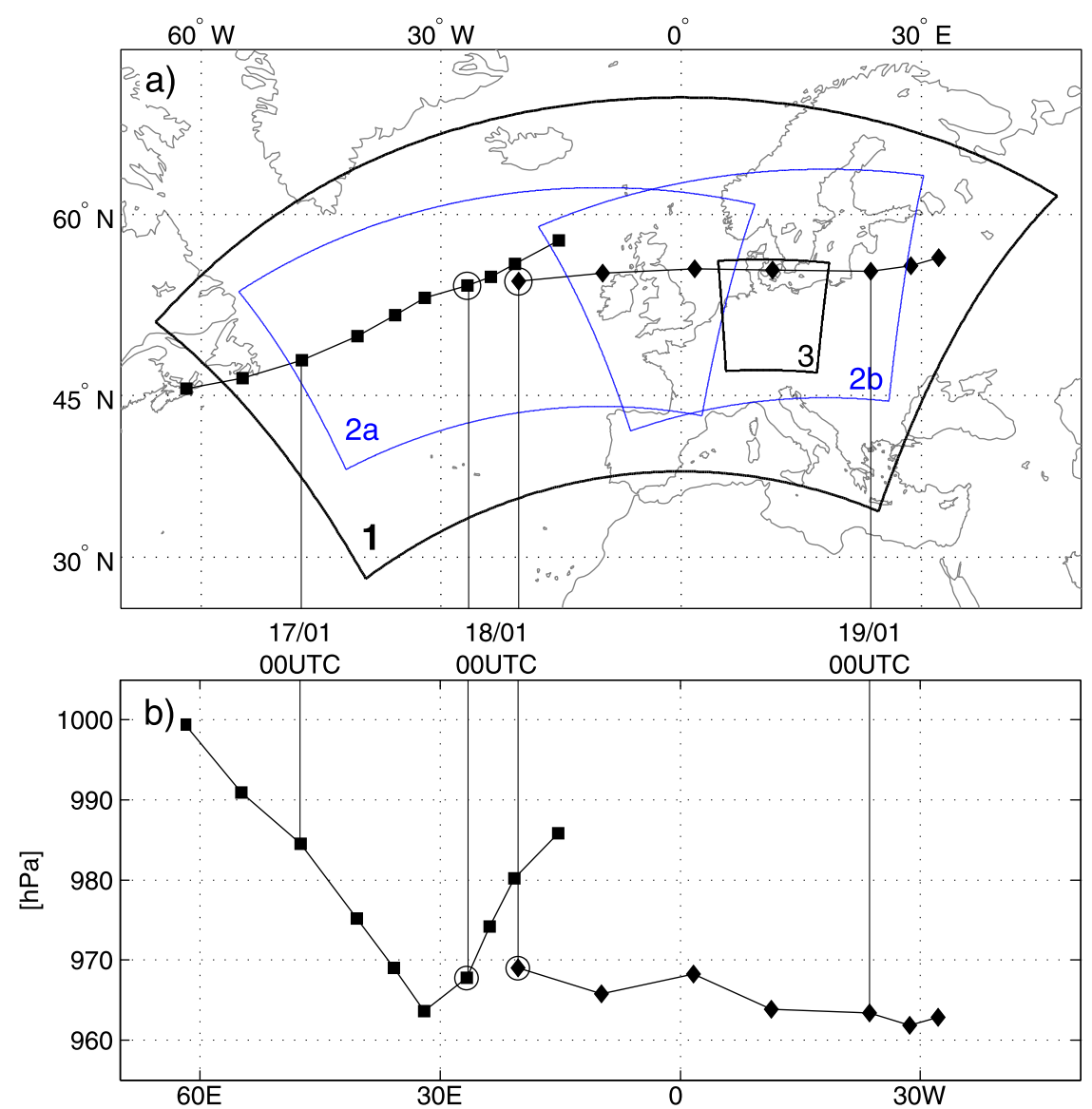

FIG. 1. The 6-hourly cyclone (a) location and (b) core pressure evolution for Kyrill I (squares) and Kyrill II (diamonds) from ERA-Interim. Data range from 1200 UTC 16 Jan to 1200 UTC 19 Jan. CCLM domains for simulations with 25-km (domain 1, black), 7-km (domain $2 \mathrm{a}$ and $2 \mathrm{~b}$, blue), and 2.8-km (domain 3, black) grid spacing are outlined in (a). Black circles mark points where Kyrill I and II co-occur for the first time.

Over eastern Germany, the Czech Republic, and Poland a total of eight (including three F3) tornado reports were verified [cf. the European Severe Weather Database (ESWD); see Dotzek et al. (2009)]. Following the criteria of Johns and Hirt (1987), Kyrill II has even been classified as a cold-season derecho in Europe (cf. Gatzen et al. 2011). The strong intensity of Kyrill II, particularly over eastern Germany, is also indicated by a dry intrusion penetrating close to the surface in the vicinity of the cold front of Kyrill II (Fink et al. 2009). The potential impacts of dry intrusions on extratropical cyclones and cold frontal rainbands have been described by Browning and Reynolds (1994), Browning and Golding (1995), and Browning (1997). The main effect is the generation of potential instability when cool and dry descending air overruns the warm conveyor belt in front of the cold front. A dry intrusion can be identified by (i) a "dry slot" or "dark zone" in the water vapor channel (e.g., Young et al. 1987), and (ii) downward advection of dry air with enhanced PV from the tropopause region (Browning 1997).

Methods for the estimation of wind gusts associated with the passage of windstorms, important for example, for impact studies or loss estimations, using mesoscale modeling or statistical approaches, are documented in Brasseur (2001), Goyette et al. (2003), De Rooy and Kok (2004), Friederichs et al. (2009), and Born et al. (2012). Methods for the estimation of wind gusts from mesoscale model outputs can be partitioned into (i) the relation of wind gusts to mean wind speed based on a gust factor (Durst 1960; Wieringa 1973), (ii) the downward transition of higher-level boundary layer momentum (Brasseur 2001), and (iii) the interpretation of gusts as the sum of the mean wind speed and a wind component related to the turbulent kinetic energy (TKE; Born et al. 2012). Schulz and Heise (2003) utilized the wind drag in terms of friction velocity when TKE was not available. 
The objectives of this study are the following:

- Document the kinematic environment and dynamical forcing leading to the uncommon formation of the secondary cyclone Kyrill II along the occluded front of parent low Kyrill I.

- Quantify the influence of diabatic processes on the intensity of Kyrill II using sensitivity experiments in which latent heat release from the convection parameterization scheme is withheld.

- Characterize the boundary layer conditions to determine the cause of the strong wind gusts along the cold front over Germany.

To answer these questions, modeling efforts with a regional climate model (COSMO-CLM) using reanalysis data as boundary conditions are undertaken. Section 2 describes the data and the regional model used in this study. In section 3, a short validation of the COSMOCLM simulations is carried out and the mechanisms, particularly for secondary cyclogenesis of Kyrill II, are considered. Section 4 focuses on the move of Kyrill II toward eastern Europe and the model resolution dependence of the generation of strong wind gusts along the distinctive cold front over northern Germany. A summary and further discussion of the main results are presented in the final section (section 5).

\section{Data and numerical model}

The numerical model used for the investigation of Kyrill I and Kyrill II is the nonhydrostatic regional Consortium for Small-Scale Modeling (COSMO) model (http://www. cosmo-model.org) in its Climate Limited-area Model version 4.8, subversion 17 (hereafter CCLM; Rockel et al. 2008). The COSMO model, developed by the German Weather Service [Deutscher Wetterdienst (DWD)], is in use for regional weather prediction by several European weather services. Using an identical formulation of the dynamical core and physical parameterizations, the only difference between the CCLM and the operational model version is that neither data assimilation nor latent heat nudging are performed in the former. The physical parameterizations include enhanced subgrid-scale turbulence (Baldauf et al. 2011) based on the level-2.5 scheme by Mellor and Yamada (1982), longwave and shortwave radiation (Ritter and Geleyn 1992), convection (Tiedtke 1989), and cloud microphysics (Doms et al. 2011).

The successful reproduction by the CCLM of windstorms affecting Europe has been documented in Born et al. (2012) and Ludwig et al. (2014). To obtain highresolution model output a one-way nesting approach is used with three model resolutions. The model integrations are all initialized using 6-hourly ERA-Interim reanalysis data (Dee et al. 2011) as lateral boundary conditions. Therefore, the full T255 spectral resolution is transformed onto a $0.75^{\circ} \times 0.75^{\circ}$ longitude/latitude grid with 60 layers in the vertical, which can be processed by the numerical model. In a first step, the 6-hourly ERAInterim data are utilized as boundary data to force a CCLM run with a horizontal grid spacing of $0.22^{\circ}$ (approximately $25 \mathrm{~km}$ ). The domain covers the North Atlantic sector and most parts of Europe on a rotated longitude-latitude grid (Fig. 1a). In a second step the 25-km grid spacing CCLM run provides boundary conditions for higher-resolution CCLM runs with $0.0625^{\circ}$ horizontal grid spacing (approximately $7 \mathrm{~km}$ ). A final nesting step is undertaken to simulate the cold front with a convection permitting (i.e., with switched off convection parameterization) horizontal grid spacing of $0.025^{\circ}$ (approximately $2.8 \mathrm{~km}$ ). In addition to the horizontal refinement, the number of vertical layers is enhanced from $35(25 \mathrm{~km})$ to $40(7 \mathrm{~km})$ to $50(2.8 \mathrm{~km})$, respectively. Vertical levels are irregularly distributed with height, with the highest vertical resolution in the boundary layer. The coarsest simulation starts at 1200 UTC 16 January and lasts for $72 \mathrm{~h}$ until 1200 UTC 19 January 2007 . Hourly output data are stored for further analysis. The subsequent high-resolution CCLM simulations are conducted for two different domains designed to capture the secondary cyclogenesis and passing of the cold front over Germany, respectively. The investigation of the secondary cyclogenesis proceeds over a domain centered over the eastern North Atlantic Ocean (Fig. 1a, domain 2a; CCLM simulation starting at 1800 UTC 16 January). The investigation of the maintenance of Kyrill II well into eastern Europe and the vigorous cold front with severe (convective) gusts over Germany proceeds over a domain centered over continental Europe (Fig. 1a, domain 2b; CCLM simulation starting at 0000 UTC 18 January). Also here hourly output data are stored for further analysis. Finally, a domain covering Germany (Fig. 1, domain 3) was chosen for the highest-resolution (convective permitting) simulation between 1200 UTC 18 January and 0600 UTC 19 January. Here, 15-min output data are stored to enable a more detailed analysis, particularly about the structure of the cold front and simulated wind (gusts) fields.

To quantify the influence of diabatic heating on the formation of Kyrill II, sensitivity studies with reduced latent heat release [reduced by $25 \%$ (LH75), $50 \%$ (LH50), 75\% (LH25), and 100\% (LH00)] have been conducted using the coarsest-resolution $(25-\mathrm{km}$ grid spacing) model configuration. The reduction of latent heat release (both evaporation/condensation and fusion/ sublimation) is limited to the convection scheme, since separate analysis of convective- and grid-scale diabatic heating rates reveals that most of the diabatic heating is 
through convection (cf. Fig. 5) in the vicinity of emerging Kyrill II.

Potential vorticity [in potential vorticity units (PVU), $\left.1 \mathrm{PVU}=\mathrm{K} \mathrm{kg}^{-1} \mathrm{~m}^{2} \mathrm{~s}^{-1}\right]$ is calculated as a diagnostic quantity using the output of the CCLM simulations. The calculation of potential vorticity on isobaric surfaces follows Dickinson et al. (1997):

$\mathrm{PV}=-g \frac{\partial \theta}{\partial p}\left(f+\frac{\partial v}{\partial x}-\frac{\partial u}{\partial y}\right)+g\left(\frac{\partial v}{\partial p} \frac{\partial \theta}{\partial x}-\frac{\partial u}{\partial p} \frac{\partial \theta}{\partial y}\right)$.

Here, $g$ is gravity, $\theta$ represents the potential temperature, $f$ is the Coriolis parameter, $p$ is the pressure level, and $u$ and $v$ represent the zonal and meridional components of the wind, respectively. To investigate the influence of diabatic heating on the generation of low-level PV, the diabatic PV rate (DPVR) is computed following Eq. (2) of Joos and Wernli (2012), converted to pressure as the vertical coordinate [see also Martin (2006)]:

$$
\mathrm{DPVR}=\frac{d}{d t} \mathrm{PV} \approx-g \eta_{p} \frac{\partial}{\partial p}(\mathrm{DHR}),
$$

where $\eta_{p}$ is the vertical component of the absolute vorticity and the total (convective and nonconvective) diabatic heating rate (DHR) is obtained from the CCLM simulations.

The alongfront stretching deformation [following Renfrew et al. (1997)] is used to investigate the kinematic environment of the front where Kyrill II forms and is calculated as

$$
E_{\mathrm{str}}=\frac{\partial v}{\partial y_{f}}
$$

Since stretching deformation is a non-Galilean invariant quantity, the coordinates are rotated into a frontal coordinate system with $y_{f}$ representing the alongfront direction. Here, the simulated (or "observed") wind field is used, which is a simplification compared to Bishop (1996) who considered a separation into frontal and environmental wind fields. Although the calculation of the stretching deformation by means of the observed wind field exhibits higher variation with regard to the frontal orientation (Renfrew et al. 1997), this approach permits us to evaluate qualitatively if the kinematic environment along the front is favorable for the development of a frontal cyclone. In addition, the frontogenesis function (Petterssen 1936), including horizontal divergence and the total deformation, is used to investigate whether the wind field is frontogenetic or frontolytic. Following Keyser et al. (1988), the frontogenesis parameter is physically a good choice since frontogenesis is partitioned between fundamental kinematic quantities that are invariant with respect to coordinate transformations.

As stated in section 1, a detailed analysis of the mesoscale features associated with the cold front of Kyrill II on 18 January is one of the objectives of this study. Wind and gust data from 121 stations from the German Weather Service (DWD) for the period between 1200 UTC 17 January and 1200 UTC 19 January are considered. To analyze the gusts along the strong cold front, the gradient Richardson number (Ri) is used to characterize whether the boundary layer flow is turbulent $(\mathrm{Ri}<0.25)$ or stable $(\mathrm{Ri}>1.0)$ (e.g., Schrage and Fink 2012). A gradient Richardson number in the range $0.25<\mathrm{Ri}<1.0$ marks the transition between stable and turbulent flow:

$$
\operatorname{Ri}=\frac{\frac{g}{T_{v}} \frac{\partial \theta_{v}}{\partial z}}{\left(\frac{\partial u}{\partial z}\right)^{2}+\left(\frac{\partial v}{\partial z}\right)^{2}}
$$

Here, $T_{v}$ is the virtual temperature, $\theta_{v}$ is the virtual potential temperature, and $z$ is the height.

Furthermore, two different diagnostic gust parameterizations for wind gust estimation (both already implemented in CCLM) are considered to obtain areawide gust distributions at high resolution. The standard method for estimating gusts in the CCLM (Schulz and Heise 2003; Schulz 2008) depends on the wind speed at 30-m height and the friction velocity $u_{*}$ :

$$
v_{\text {DWD }}=\left|v_{30 \mathrm{~m}}\right|+3.0 \times 2.4 \times u_{*},
$$

with the empirical factors 3.0 and 2.4 motivated by Prandtl layer theory (Panofsky and Dutton 1984). In the alternative TKE approach [see Born et al. (2012) for a detailed description], the relation between mean TKE, denoted $\bar{q}$, and gusts, $v_{\mathrm{TKE}}$, is

$$
v_{\mathrm{TKE}}=\sqrt{2 E_{\max }}=\bar{v}+2 \sqrt{\bar{q}}+\varepsilon_{v},
$$

where $E_{\max }$ is the maximum kinetic energy, $\bar{v}$ is the mean wind speed ( $30 \mathrm{~m}$ above the surface), and $\varepsilon_{v}$ is the stochastic subgrid-scale part of $v_{\max }$.

\section{General model performance and development of the secondary cyclone}

\section{a. Validation of the CCLM simulations}

In this subsection, the CCLM-simulated cyclone tracks and intensities and the synoptic-scale structure are validated for the Kyrill case. Figure 2 shows a comparison of the cyclone tracks (Fig. 2a) and core pressure evolution 


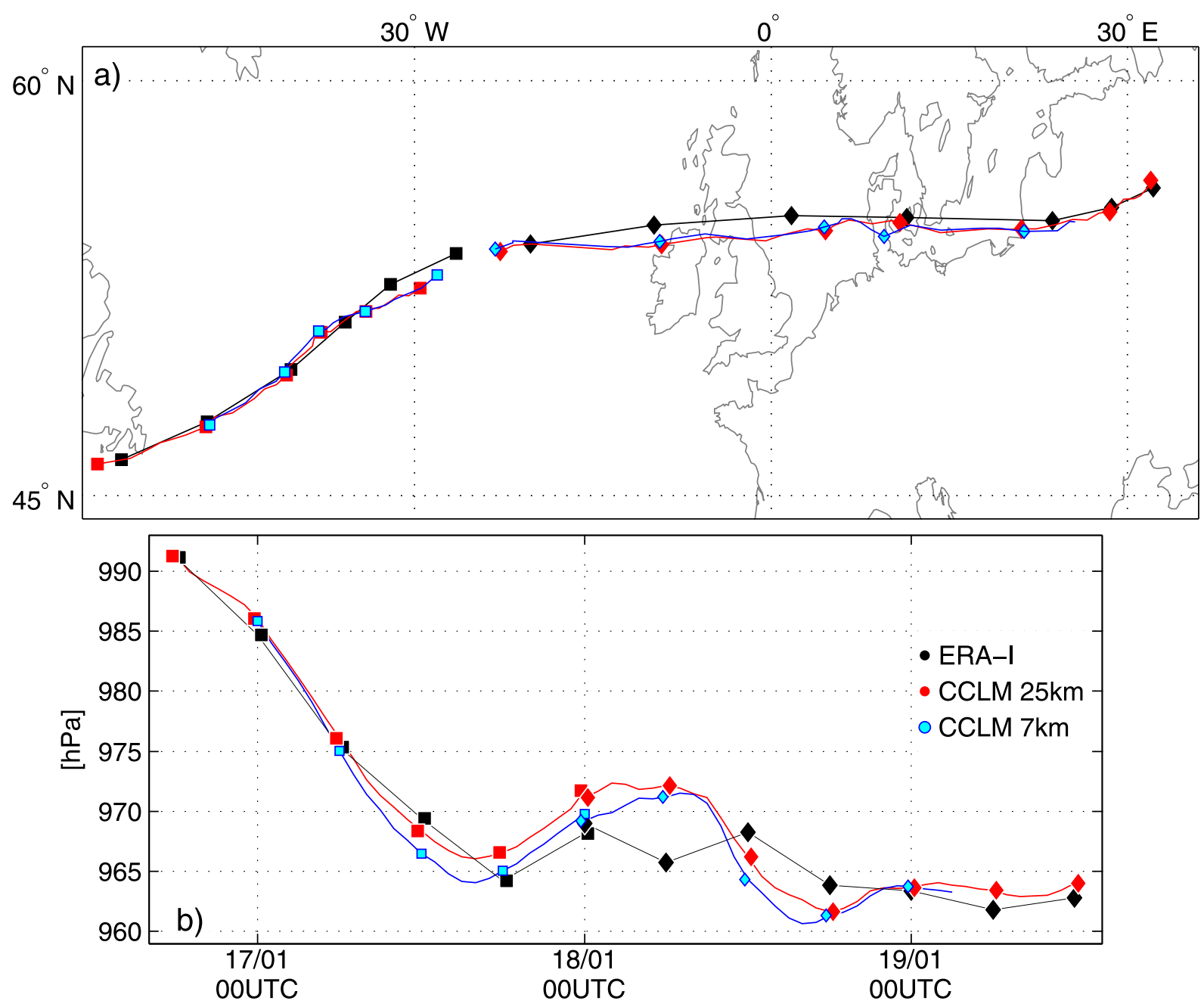

FIG. 2. Comparison of (a) cyclone tracks and (b) core pressure evolution of CCLM simulations for Kyrill I and II: The 6-hourly ERAInterim data for Kyrill I/ Kyrill II (black squares/diamonds), hourly CCLM 25-km grid spacing data for Kyrill I/ Kyrill II (red squares/ diamonds each $6 \mathrm{~h}$ ), and hourly CCLM 7-km grid spacing data for Kyrill I/ Kyrill II (blue squares/diamonds each $6 \mathrm{~h}$ ). All Kyrill I (Kyrill II) tracks in (a) end (start) at 0000 UTC 18 Jan.

(Fig. 2b) of Kyrill I and Kyrill II obtained from the CCLM with 25- and 7-km grid spacing and ERAInterim data. The simulations reproduce the storm with reasonable skill. The location of Kyrill I and II at the point where they coexist is shifted slightly to the west (more so in the $25-\mathrm{km}$ grid spacing simulation), but both the coarse- and fine-resolution simulations reproduce the track of Kyrill II very well. The evolution of core pressure shows an earlier pressure minimum for both simulations than in the reanalysis. However, the simulation data are available each hour; when comparing 6-hourly values only, the timing of the pressure minimum is the same as in the reanalysis. The core pressure of the 7- $\mathrm{km}$ grid spacing simulation reaches a slightly deeper minimum than that of the $25-\mathrm{km}$ simulation for both Kyrill I and II.
In Fig. 3, the synoptic-scale structure of the $25-\mathrm{km}$ grid spacing simulation of the evolution of Kyrill is depicted. A latitudinal band of strong wind speed (locally exceeding $90 \mathrm{~m} \mathrm{~s}^{-1}$ ) marks the upper-tropospheric jet stream on 1200 UTC 17 January (Fig. 3a), 0000 UTC 18 January (Fig. 3b), and 1200 UTC 18 January (Fig. 3c). The corresponding surface cyclone location (mean sea level pressure in Figs. 3g-i, marked by Arabic numbers 1 and 2 throughout Fig. 3) indicates a favorable location relative to the upper-level jet stream; the surface cyclone is situated underneath the left exit region of the jet streak, known to be a favorable location for upper-level divergence (cf. Figs. 4a,b) (e.g., Uccellini and Johnson 1979). Together with the eastward-moving jet stream, a dry intrusion develops (cf. Figs. 3c,f,i in Fink et al. 2009) with its tip on this 500-hPa surface following the 
1200 UTC 17 January

0000 UTC 18 January

1200 UTC 18 January
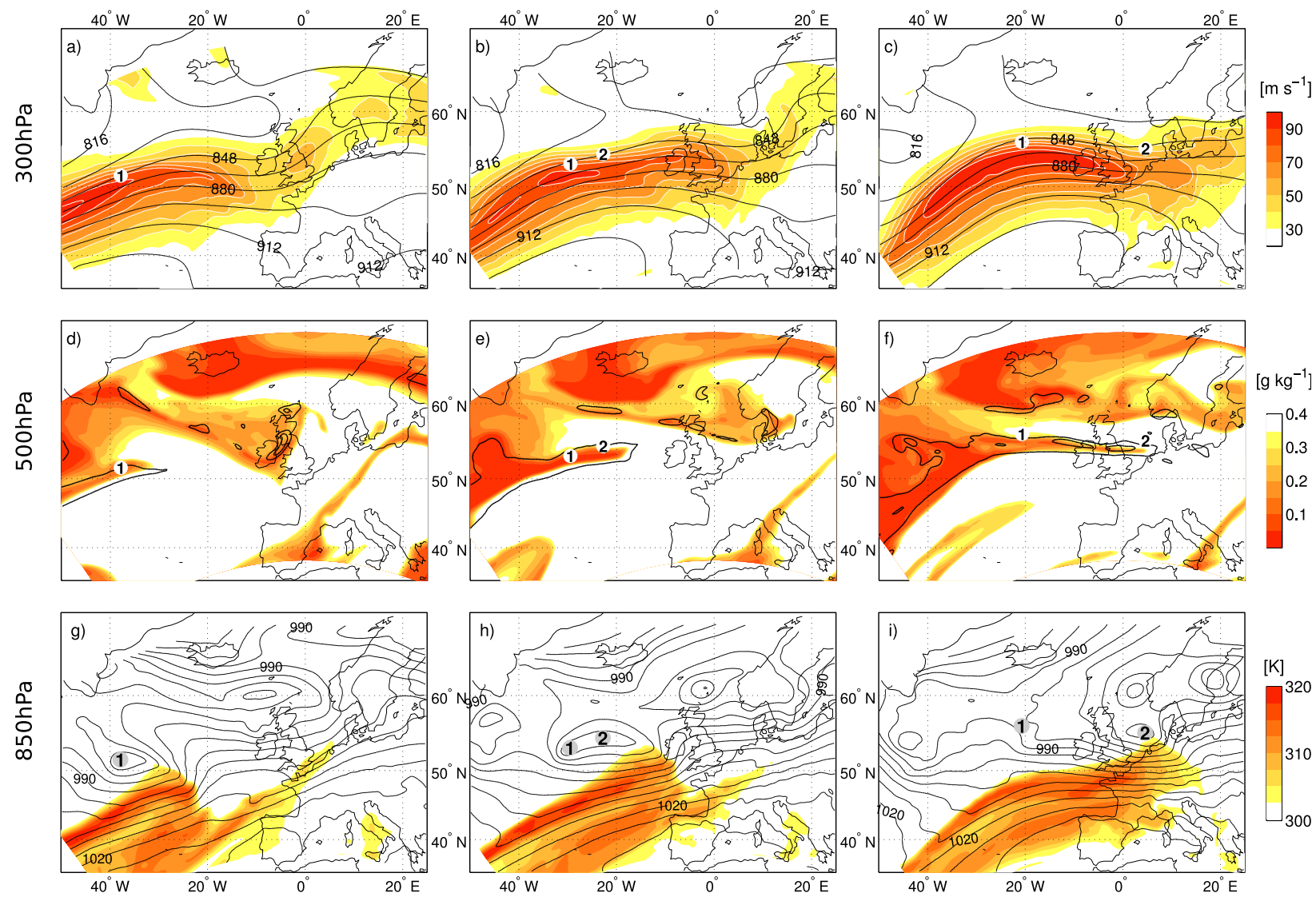

FIG. 3. Synoptic-scale overview for 25-km grid spacing simulation of Kyrill I and II at (a),(d),(g) 1200 UTC 17 Jan; (b),(e),(h) 0000 UTC 18 Jan; and (c),(f),(i) 1200 UTC 18 Jan. (a)-(c) Jet stream $\left(\mathrm{m} \mathrm{s}^{-1}\right)$ (shaded) and geopotential height (black isolines each 16 dam) at $300 \mathrm{hPa}$. (d)-(f) Specific humidity ( $\mathrm{g} \mathrm{kg}^{-1}$ ) (shaded) and potential vorticity (isolines at 1.5 and $3.5 \mathrm{PVU}$ ) at $500 \mathrm{hPa}$. (g)-(i) Equivalent potential temperature $\theta_{e}(\mathrm{~K})$ (shaded) at $850 \mathrm{hPa}$ and mean sea level pressure (hPa) (isolines each $5 \mathrm{hPa}$ ). Numbers 1 and $2 \mathrm{mark}$ the corresponding cyclone positions of Kyrill I and II, respectively.

position of the surface cyclone beneath (Figs. 3d-f) toward central Europe. The dry intrusion is characterized by (i) low values of the specific humidity and (ii) by high $\mathrm{PV}$ values, indicating descending air from the tropopause region. The 850 -hPa $\theta_{e}$ field (Figs. $3 \mathrm{~g}-\mathrm{i}$ ) shows the incorporation of warm and humid air masses at the southern flank of the cyclone, potentially providing energy to the storm in terms of latent heat release if this boundary layer air is lifted. The sensitivity of the development of strong extratropical cyclones to warm and humid air masses has already been demonstrated by Danard (1964) and Gall (1976), and more recently by Fink et al. (2012), Dacre and Gray (2013), Ludwig et al. (2014), and Doyle et al. (2014). To summarize, the CCLM simulations provide realistic features in terms of large-scale atmospheric patterns and temporal storm development and thus are suitable for further investigation of this secondary cyclogenesis event and storm-relevant details.

\section{b. Development of the secondary cyclone Kyrill II}

In this subsection, the focus is on the mechanism and location of the secondary cyclogenesis and thus the formation of Kyrill II. Results shown here are derived from the 7-km grid spacing CCLM simulation covering domain 2a. Figure 4 shows selected model fields at 0000 and 0600 UTC 18 January. At upper levels $(300 \mathrm{hPa})$, the eastern edge of the strong jet stream with wind speeds up to $80 \mathrm{~m} \mathrm{~s}^{-1}$ is located over the British Isles (Figs. 4a,b). Maximum values of upper-level divergence exceeding $6 \times 10^{-5} \mathrm{~s}^{-1}$ are found in the left exit region of the jet streak. This region is, therefore, favorable for surface pressure falls, rising motion, and latent heat release in the ascending airstream; all of these are favorable for the intensification and maintenance of a lowlevel cyclone. Over the Atlantic Ocean, simulated wind speeds are even faster (exceeding $90 \mathrm{~m} \mathrm{~s}^{-1}$ ). The western parts of the domain (up to the location where Kyrill II 

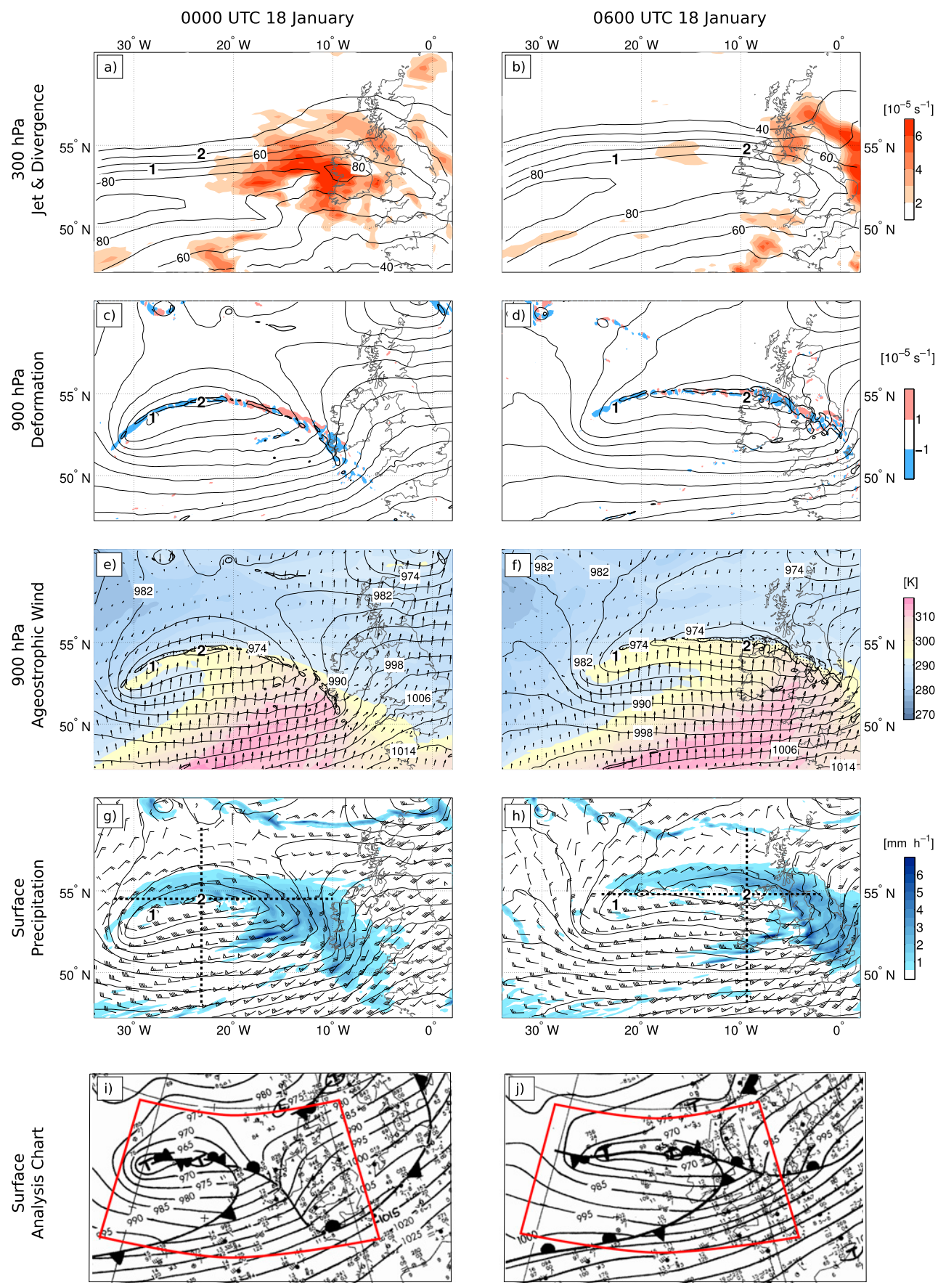

FIG. 4. Frontal structure and forcing during secondary cyclogenesis for 7-km grid spacing simulation at (left) 0000 UTC 18 Jan and (right) 0600 UTC 18 Jan. (a),(b) Horizontal wind ( $\mathrm{m} \mathrm{s}^{-1}$ ) speed (contour lines starting at $40 \mathrm{~m} \mathrm{~s}^{-1}$, than each $10 \mathrm{~m} \mathrm{~s}^{-1}$ until $90 \mathrm{~m} \mathrm{~s}^{-1}$ ) and divergence $\left(10^{-5} \mathrm{~s}^{-1}\right)$ (shaded) at $300 \mathrm{hPa}$. (c), (d) Alongfront stretching deformation of the wind field $\left(10^{-5} \mathrm{~s}^{-1}\right)$ (shaded) at $900 \mathrm{hPa}$, potential vorticity (stippled area inside bold black line marks regions with $\mathrm{PV}>2 \mathrm{PVU}$ between 850 and $950 \mathrm{hPa}$ ), and mean sea level pressure (hPa) (contour lines each $4 \mathrm{hPa}$ ). (e),(f) Potential vorticity [as in (c),(d)] and equivalent potential temperature (K) (shaded) at $850 \mathrm{hPa}$, ageostrophic wind component (vectors) at $900 \mathrm{hPa}$, and mean sea level pressure [as in (c),(d)]. (g),(h) Precipitation amount $\left(\mathrm{mm} \mathrm{h}^{-1}\right)$ for the preceding hour, wind barbs for wind speed $\left(\mathrm{m} \mathrm{s}^{-1}\right)$ at $975 \mathrm{hPa}$ (triangle $22.5 \mathrm{~m} \mathrm{~s}^{-1}$, long dash $5 \mathrm{~m} \mathrm{~s}^{-1}$, and short dash $2.5 \mathrm{~m} \mathrm{~s}^{-1}$ ), and mean sea level pressure [as in (c),(d)]. Dotted black lines in (g) and (h) denote location of cross sections depicted in Fig. 6. Numbers 1 and 2 mark the corresponding cyclone positions of Kyrill I and II respectively. (i),(j) Surface analysis charts provided by DWD [red border marks section for (a)-(h)]. 
emerges at the occluded front of Kyrill I) are characterized by negative (frontolytic) stretching deformation of the horizontal wind field at $900 \mathrm{hPa}$ (Fig. 4c) (for clarification of frontal boundaries, surface analysis charts from DWD are included; Figs. 4i,j). Frontolytic stretching deformation along a low-level PV band favors the breaking up of the PV band (Dacre and Gray 2006) and thus supports secondary cyclogenesis (Parker 1998a,b). Before (not shown) and during the development of Kyrill II, the band of negative stretching deformation is coherent in the region of the emerging low pressure center (Fig. 4c) potentially leading to several separated PV maxima. Additionally, the frontogenesis parameter (Petterssen 1936) is negative in the vicinity of emerging Kyrill II, documenting that the environmental flow is frontolytic (not shown). Six hours later, the PV band broadens as Kyrill II intensifies (Fig. 4d), mainly due to continuing diabatic heating along the occluded front (cf. Figs. 5a,b) Additionally, negative stretching deformation remains in the vicinity of Kyrill I, leading to the dissipation of the associated PV band. Figures $4 \mathrm{e}$ and 4f show the distribution of warm and humid air masses along the occluded front. The convergence of the ageostrophic wind component along the PV band implies lifting of these air masses and their relevance for the development of Kyrill II. The cold front extending southwestward from the eastern edge of the low pressure center toward $50^{\circ} \mathrm{N}, 20^{\circ} \mathrm{W}$ in Figs. $4 \mathrm{~g}$ and $4 \mathrm{~h}$ is associated with a cyclonic wind shift but, unlike the warm front, it is only weakly active with minimal precipitation at the times shown. At the intersection of the warm and the cold front the triple point is marked by the strongest precipitation rates (Figs. 4g,h). Since the triple point is southeast of the region where Kyrill II develops, we state that Kyrill II develops along the occluded front of the parent low Kyrill I [a rare case not described in Parker (1998a) but mentioned in Neiman et al. (1993)]. Kyrill fits nicely into the type- 2 category of the secondary cyclone classification scheme defined by Ayrault et al. (1995); this type is characterized by a strong warm front and frontolytic flow.

The evaluation of east-west- and north-south-orientated vertical cross sections centered along the cyclone center provides further insights into the environmental characteristics during secondary cyclogenesis. Figure 5a shows vertically orientated regions of strong DHRs and enhanced PV extending along the occluded front. The strong DHRs along the occluded front, where warm air has been lifted, are associated with the region of intensive precipitation (cf. Fig. 4g). Slightly west of $20^{\circ} \mathrm{W}$, a narrow band of strong DHRs is located in the vicinity of emerging Kyrill II, which is also visible in a north-south cross section at the same time (Fig. 5c). Aloft of emerging Kyrill II, a coherent region of enhanced PV, associated with strong DHRs, is obvious up to $700 \mathrm{hPa}$. The region with strong DHRs between $51^{\circ}$ and $52^{\circ} \mathrm{N}$ is associated with the trailing cold front of Kyrill I. Six hours later, Kyrill II is located at $54.8^{\circ} \mathrm{N}, 9.2^{\circ} \mathrm{W}$. Aloft, enhanced PV and strong DHRs coexist, consistent with a hypothesized continued role of diabatic forcing in the intensification of Kyrill II (Figs. 5b,d). During the intensification, the dynamic tropopause has locally descended down to $650 \mathrm{hPa}$.

Separation of the convective- and grid-scale DHRs reveals that latent heat release by convective processes played the major role during the formation of Kyrill II. The narrow vertical strip of strong DHRs above the surface cyclone disappears when only grid-scale latent heat release is considered (Figs. 5e, f). The importance of diabatic heating on the generation of low-level PV is also obvious in Fig. 5. The collocation of high values of $\eta_{p}$ and a downward decrease in DHR causes high diabatic PV generation [cf. Eq. (2)] below $800 \mathrm{hPa}$ on 0000 UTC 18 January 2007 in the area where Kyrill II developed (Fig. 5g). A separate analysis of convective and nonconvective DHRs reveals a clear dominance of convective over nonconvective (grid scale) generation of PV (not shown). At 0600 UTC the maximum of $\eta_{p}$ tilts away from the DHR maximum in the vertical, thereby reducing DPVR. Even though the DPVR is reduced at 0600 UTC (Fig. 5h), the same conclusions can be drawn as for 0000 UTC. This motivated a set of sensitivity experiments with the coarsest-resolution model configuration (25-km grid spacing) in which latent heat release is reduced, but only in the convective parameterization scheme. Results of the sensitivity experiments are summarized in Fig. 6. The locations of the first coexistence of Kyrill I and Kyrill II are depicted in Fig. 6a; the formation of Kyrill II (defined as the first closed isobar with a 1-hPa interval based on the hourly model output) is retarded by about $3 \mathrm{~h}$ in the sensitivity experiments. Likewise, a shift to the east of Kyrill II is discernable with decreasing latent heat release (except for the LH50 experiment). The decrease of latent heat release also leads to a systematic weakening of the mean sea level pressure minima for Kyrill I (Fig. 6b) being strongest for LH00 with $4.5 \mathrm{hPa}$. The reduction of the mean sea level pressure minima for Kyrill II is considerably stronger than for Kyrill I (Fig. 6c). At the formation time of Kyrill II, the difference between CNTRL and LH00 amounts to $7.5 \mathrm{hPa}$. Also, the subsequent development of Kyrill II is weaker throughout the sensitivity experiments, leading to a maximum difference in mean sea level pressure minimum between CNTRL and LH00 of $17.1 \mathrm{hPa}$ at 1700 UTC 18 January. The additional DPVR diagnostics, together with the sensitivity 

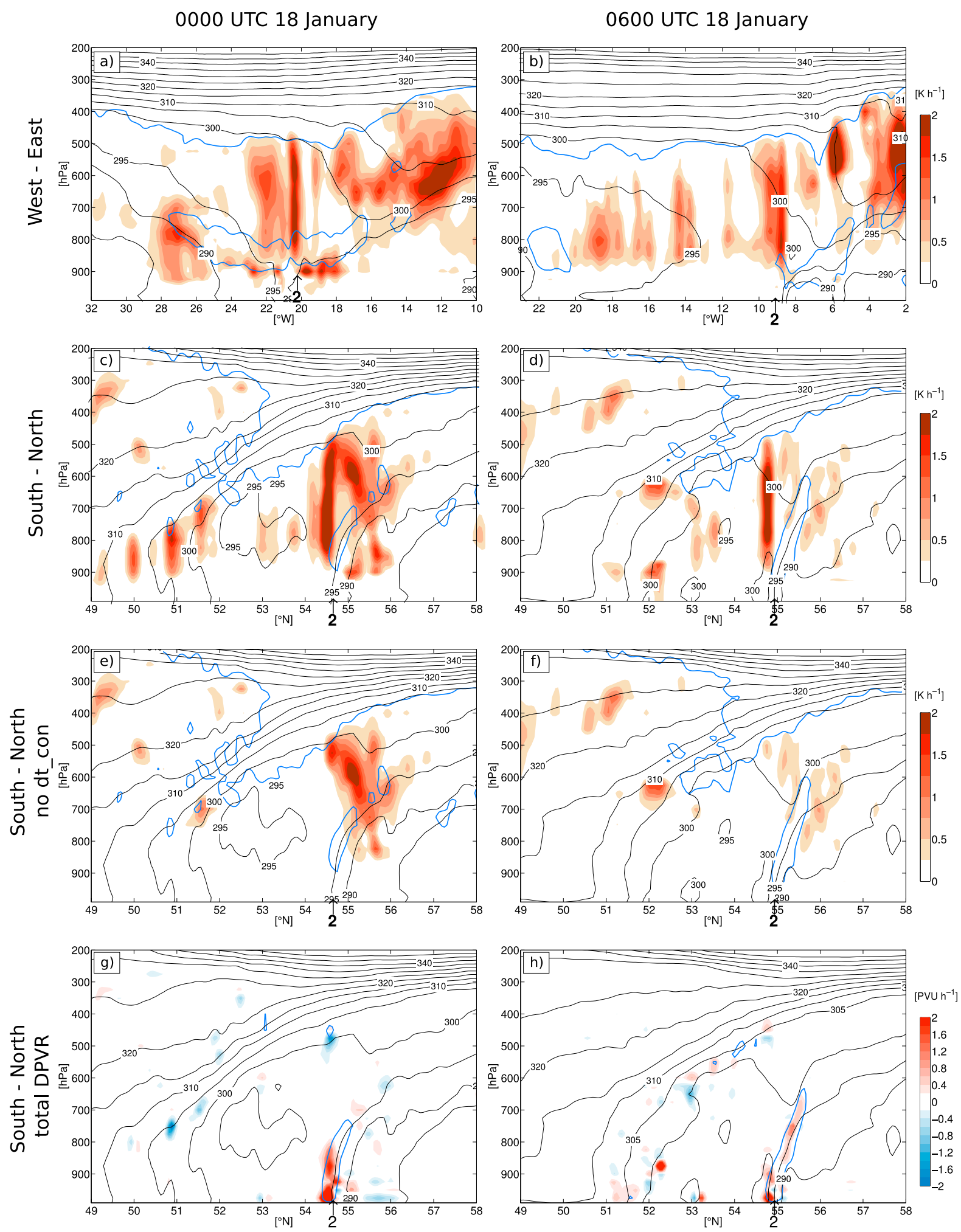

FIG. 5. West-east- and south-north-orientated vertical cross sections at (a),(c),(e),(g) 0000 UTC 18 Jan and (b),(d),(f),(h) 0600 UTC 18 Jan for 7-km grid-spacing simulation. Positions of cross sections are marked in Fig. 4. (a),(b) West-east cross sections depicting equivalent potential temperature $\theta_{e}(\mathrm{~K})$ in thin black lines (each $5 \mathrm{~K}$ ), dynamical tropopause marked by 2-PVU line (bold blue line), and regions with diabatic heating rate $\left(\mathrm{K} \mathrm{h}^{-1}\right)$ (shaded areas). (c),(d) As in (a),(b), but for south-north cross sections. (e),(f) As in (c),(d), but for diabatic heating rate from cumulus parameterization excluded. Number "2" along the abscissa marks the corresponding cyclone positions of Kyrill II. (g),(h) Total DPVR $\left(\mathrm{PVU} \mathrm{h}^{-1}\right)$ and the $z$ component of absolute vorticity $\eta_{p}$ (blue line at $0.5 \times 10^{-4} \mathrm{~s}^{-1}$ ). 

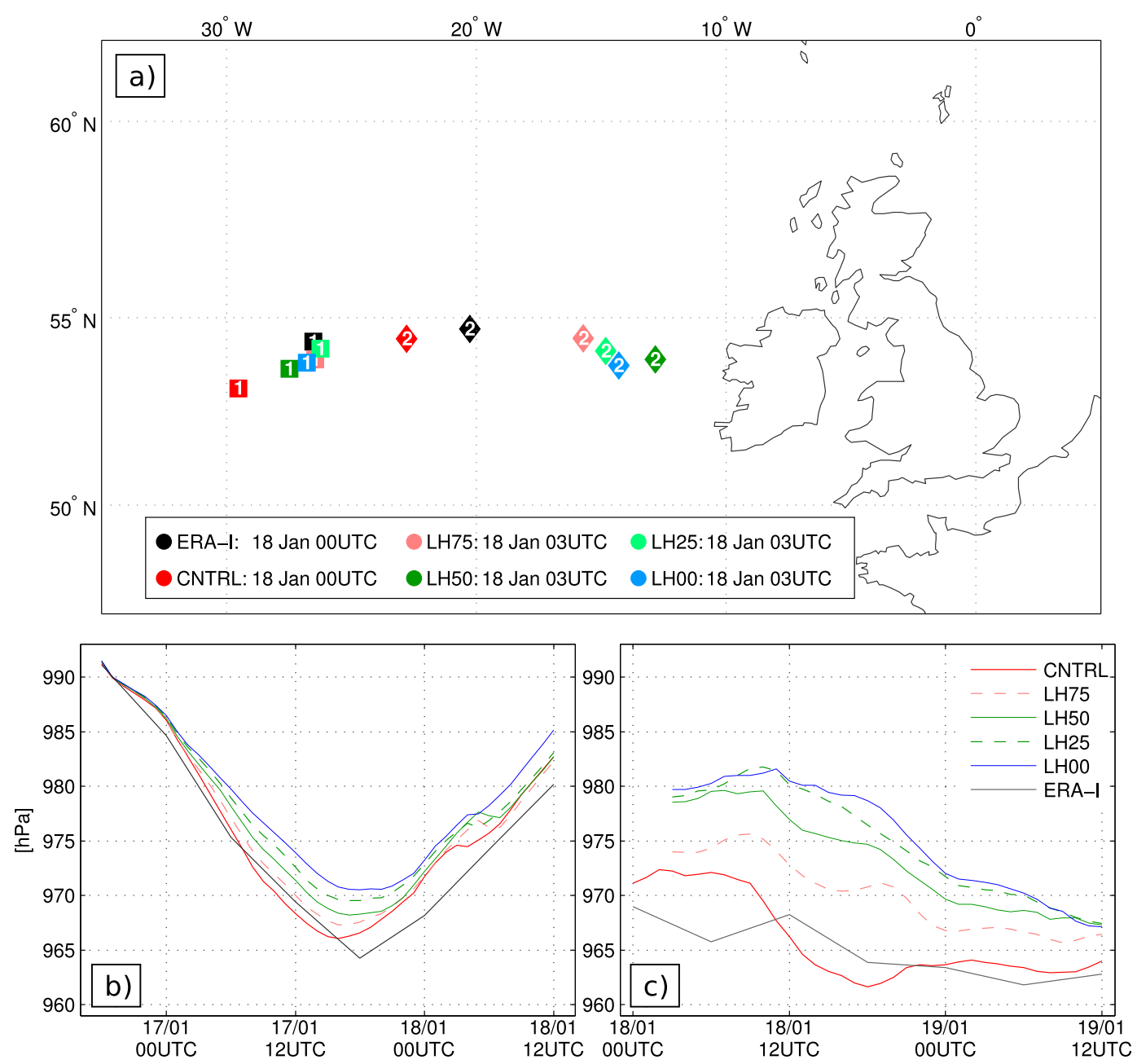

FIG. 6. (a) Synopsis of locations when Kyrill I and II co-occur for the first time for CCLM 25-km grid spacing CNTRL and sensitivity experiments with suppressed latent heat release in convection scheme. (b) Pressure progression for Kyrill I. (c) Pressure progression for Kyrill II. Color codes for lines are in (c).

studies with reduced diabatic heating through convection, lends more credence to our hypothesis that diabatic processes played an important role on the formation of Kyrill II. Nevertheless, since Kyrill II evolves even under zero latent heating in the convection scheme, diabatic processes are not able to explain the formation of Kyrill II entirely. Additional analyzes of the $300-\mathrm{hPa}$ isotachs and divergence fields verify that the upper-level kinematic environment for the control simulation and the sensitivity studies are indeed similar, such that observed differences in cyclogenesis are likely not related to differences in the upper-level forcing (not shown). Thus, we conclude that the differences between the experiments are very unlikely to be due to the small differences in the upperlevel conditions, thus supporting our hypothesis that the diabatic heating plays an important role for the secondary cyclone development. The role of combined upper-level forcing by the split jet stream is left to further research.

In summary, we have shown evidence that the formation of Kyrill II proceeds (i) along the occluded front, (ii) in a frontolytic environment with negative stretching deformation of the horizontal wind field, and (iii) is supported by diabatic processes in the mid- and particularly lower troposphere hypothetically in conjunction with a developing upper-level trough.

\section{Passing of Kyrill II over central Europe \\ a. High-resolution simulations with COSMO-CLM}

In the following hours, the storm moved farther toward Europe. An overview of the upper-tropospheric conditions that maintained the deep core pressure of Kyrill II (Fig. 1) while it passed over central Europe is 

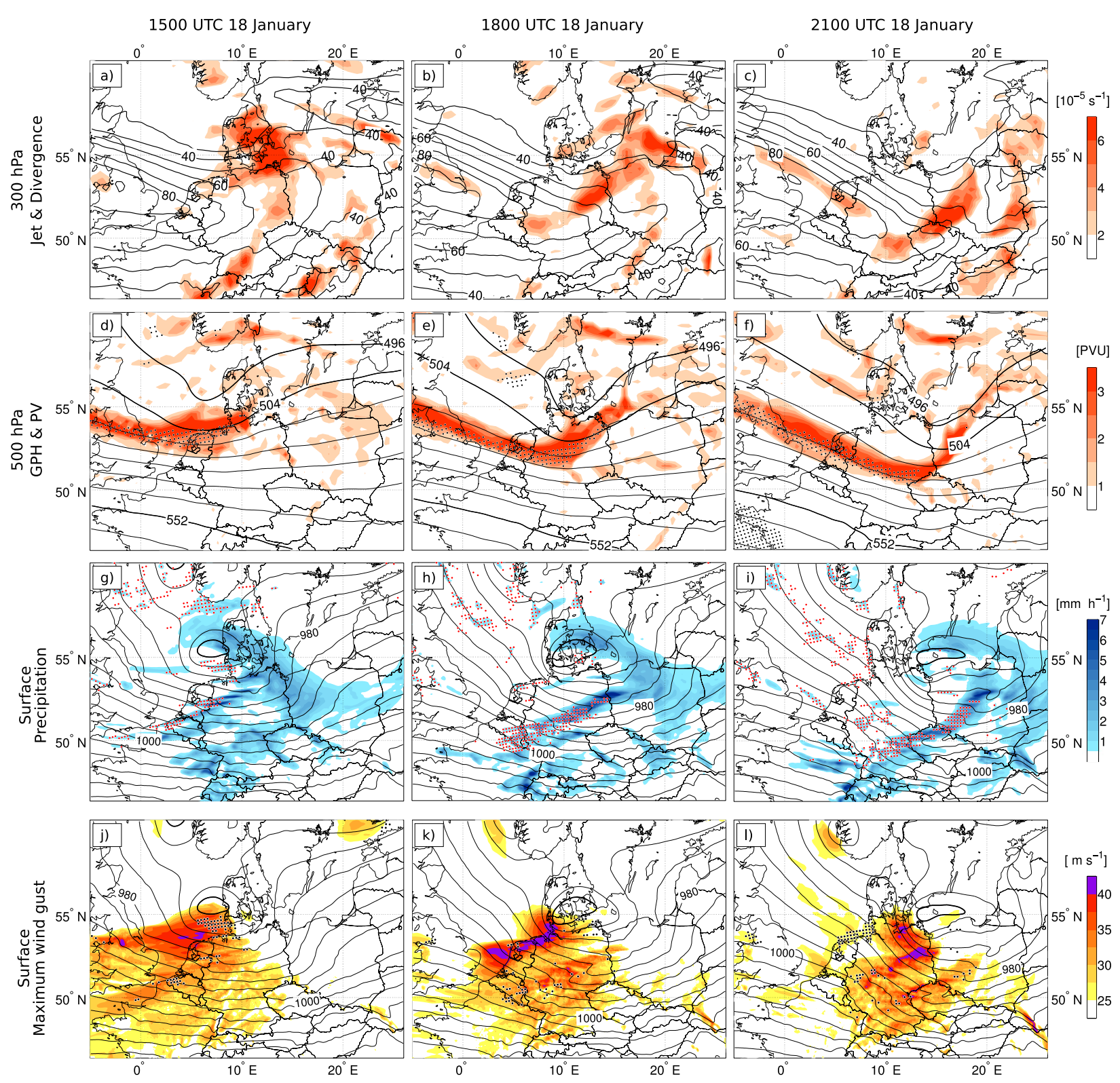

FIG. 7. Frontal forcing, structure, and wind gusts for the 7-km grid-spacing simulation of Kyrill II over central Europe at 1500,1800 , and 2100 UTC 18 Jan. (a)-(c) Jet stream $\left(\mathrm{m} \mathrm{s}^{-1}\right.$ ) (contour lines each $10 \mathrm{~m} \mathrm{~s}^{-1}$ above $30 \mathrm{~m} \mathrm{~s}^{-1}$ ) and divergence $\left(10^{-5} \mathrm{~s}^{-1}\right)(\mathrm{shaded})$ at $300 \mathrm{hPa}$. (d)-(f) Geopotential height (dam) (GPH, isolines each 8 dam), potential vorticity (PVU, shaded), and relative humidity (\%) (region less than $10 \%$ stippled) at $500 \mathrm{hPa}$. (g)-(i) Mean sea level pressure (hPa) (contour lines each $4 \mathrm{hPa}$, cyclone center isobar bold) and precipitation amount of the preceding hour $\left(\mathrm{mm} \mathrm{h}^{-1}\right)$. Grid points with convective precipitation are marked with red dots. (j)-(l) As in (g)-(i), but for maximum wind gust $v_{\mathrm{DWD}}\left(\mathrm{m} \mathrm{s}^{-1}\right)$. Grid points with convective gusts exceeding $25 \mathrm{~m} \mathrm{~s}^{-1}$ are marked with black dots.

presented using the 7-km horizontal grid spacing simulation over domain 2b. At 1500 UTC 18 January the core of the upper-level jet stream (wind speeds $>80 \mathrm{~m} \mathrm{~s}^{-1}$ ) is located over the British Isles heading toward eastern parts of Germany (Fig. 7a). At this time strong upperlevel winds exceeding $50 \mathrm{~m} \mathrm{~s}^{-1}$ are already located over northern and central Germany. As already hypothesized in Fink et al. (2009), the coexistence of a second jet streak over the Baltic States leads to very strong upperlevel divergence between the exit and entry regions of both jet streaks and is assumed to play a crucial role for the maintenance of the long-lasting deep core pressure of Kyrill II. In the following 3-6h (Figs. 7b,e and 7c,f), the shortwave disturbance and associated jet streaks are observed to move downstream toward central Europe, exceeding wind speeds of $80 \mathrm{~m} \mathrm{~s}^{-1}$ at 2100 UTC over 
Benelux and eastern parts of Germany. During this period, the upper-level divergence remains strong between the two jet streaks and Kyrill II moves along with the shortwave trough toward the east (Figs. 7g-i), reaching simulated minimum mean sea level pressures of $961.1,961.3$, and $963.0 \mathrm{hPa}$ at 1500,1800, and $2100 \mathrm{UTC}$, respectively. The frontal structures are analyzed by considering the precipitation and maximum wind gust (here $v_{\mathrm{DWD}}$ ) for each preceding hour. The warm front is characterized by uniform large-scale precipitation with hourly averaged precipitation rates hardly exceeding $3 \mathrm{~mm} \mathrm{~h}^{-1}$. In contrast, the cold front is characterized by a narrow band of both large resolved grid-scale and parameterized hourly averaged convective precipitation rates exceeding $7 \mathrm{~mm} \mathrm{~h}^{-1}$ (grid points with parameterized convective precipitation are marked by red dots). Convective precipitation is also simulated by CCLM behind the cold front, a region where it is typically observed. Simulated wind gusts are partitioned into convective and nonconvective types (grid points with convective gusts $>25 \mathrm{~m} \mathrm{~s}^{-1}$ are marked by black dots; Figs. 7j-1). At 1500 UTC, convective gusts are predominantly located south of the cyclone center, with only a few convective gusts simulated along the cold front. At 1800 UTC, an increased number of grid points exhibit convective gusts, mainly at the western tail of the cold front. Maximum gusts exceeding $40 \mathrm{~m} \mathrm{~s}^{-1}$ are simulated all along the northern shoreline of the North Sea. Along the cold front, isolated grid points have gusts exceeding $40 \mathrm{~m} \mathrm{~s}^{-1}$ with only a few of them being convective in nature. At 2100 UTC, strongest wind gusts appear in the region with enhanced pressure gradient close to the west and southwest of the cyclone center. The cold front, located along the German-Czech border, is still associated with widespread severe wind gusts exceeding $40 \mathrm{~m} \mathrm{~s}^{-1}$, particularly over the high mountain ranges of the Ore Mountains at this time.

The simulation with highest resolution (grid spacing $2.8 \mathrm{~km}$, domain 3 ) provides a more detailed view of the cold front passing Germany between 1700 and 1900 UTC. Narrow bands of strong simulated radar reflectivity exceeding values of $50 \mathrm{dBZ}$ are aligned with the cold front (Figs. 8a-c). This is in good agreement with measured radar reflectivity as shown in Fink et al. (2009, their Fig. 5). The areas with the highest reflectivity are associated with strong updrafts in excess of $0.75 \mathrm{~m} \mathrm{~s}^{-1}$ and hourly averaged precipitation rates exceeding $10 \mathrm{~mm} \mathrm{~h}^{-1}$ (Figs. 8g-i). The dry intrusion is situated directly behind the cold front during the period shown; the cold front is marked by strong simulated reflectivity. At 1700 UTC, the area beneath the dry intrusion is nearly free of precipitation. Weak postfrontal reflectivity is simulated near the North Sea coast, associated with weak hourly averaged precipitation rates $\left(<3 \mathrm{~mm} \mathrm{~h}^{-1}\right)$. Gustiness associated with the cold front is shown in Figs. 8d-f. Additionally, the locations of the three verified tornado reports over eastern Germany [cf. ESWD database, Dotzek et al. (2009)] are plotted on the maps. The first tornado (F2) was reported at Meseberg $\left(52.96^{\circ} \mathrm{N}, 13.12^{\circ} \mathrm{E}\right)$ at $1730 \mathrm{UTC}$, followed by the second $(\mathrm{F} 3)$ near Lutherberg $\left(51.87^{\circ} \mathrm{N}, 12.65^{\circ} \mathrm{E}\right)$ at 1740 UTC, and the third (also F3) at Lauchhammer $\left(51.51^{\circ} \mathrm{N}, 13.94^{\circ} \mathrm{E}\right)$ at $1830 \mathrm{UTC}$. The strongest wind gusts are located below the left exit region of the upperlevel jet stream. As stated by Rose et al. (2004), rising motions below left-exit quadrants of a jet streak are associated with the development of convection and severe weather. Their 10-year climatology reveals tornadoes primarily occur within the two exit quadrants of the jet stream, with the left-exit quadrant favored over the right-exit quadrant. The investigated case of Kyrill II is consistent with this climatology, as the observed tornadoes are located below the left exit region of the simulated jet stream. Additionally, the upper-level jet stream exhibits weak cyclonic curvature. In the case of cyclonic curvature, divergence in the left exit region becomes amplified (Moore and Vanknowe 1992). The observed tornado events are also within the region with the strongest simulated wind gusts, radar reflectivity, and upward motion at the corresponding times.

\section{b. Physical mechanisms associated with peak wind gusts along the cold front}

A detailed analysis of the mesoscale features associated with the cold front of Kyrill II over Germany on 18 January is presented in this subsection. To evaluate in detail the nature of gusts and infer the areas potentially affected by strong downdrafts, two times are considered to characterize the conditions at different locations along the cold front, particularly at lower-tropospheric levels: 1645 (Fig. 9) and 1800 UTC (Fig. 10). At 1645 UTC, the cold front extends from the federal state of NorthRhine Westphalia (NRW) toward Berlin (B) in the northeasterly direction (Fig. 9e, federal state names included). While the cold front, here identified as the region with strong horizontal $\theta_{e}$ gradient, is rather fragmented over NRW, the front is sharpened farther to the east (Fig. 9e). The regions with the strongest wind gusts, exceeding $32.7 \mathrm{~m} \mathrm{~s}^{-1}$ (definition of hurricaneforce winds), are mainly located behind (north of) the front (see also Figs. 8d-f). The vertical profiles at $51.28^{\circ} \mathrm{N}, 6.76^{\circ} \mathrm{E}$ [near station Düsseldorf, WMO 10400 , where the highest $\left(40 \mathrm{~m} \mathrm{~s}^{-1}\right)$ lowland wind gust was reported] reveal favorable lower-tropospheric conditions for the generation of the severe surface wind gusts; simulated gusts reached $34.3 \mathrm{~m} \mathrm{~s}^{-1}$ at that time. The low 
1700 UTC 18 January
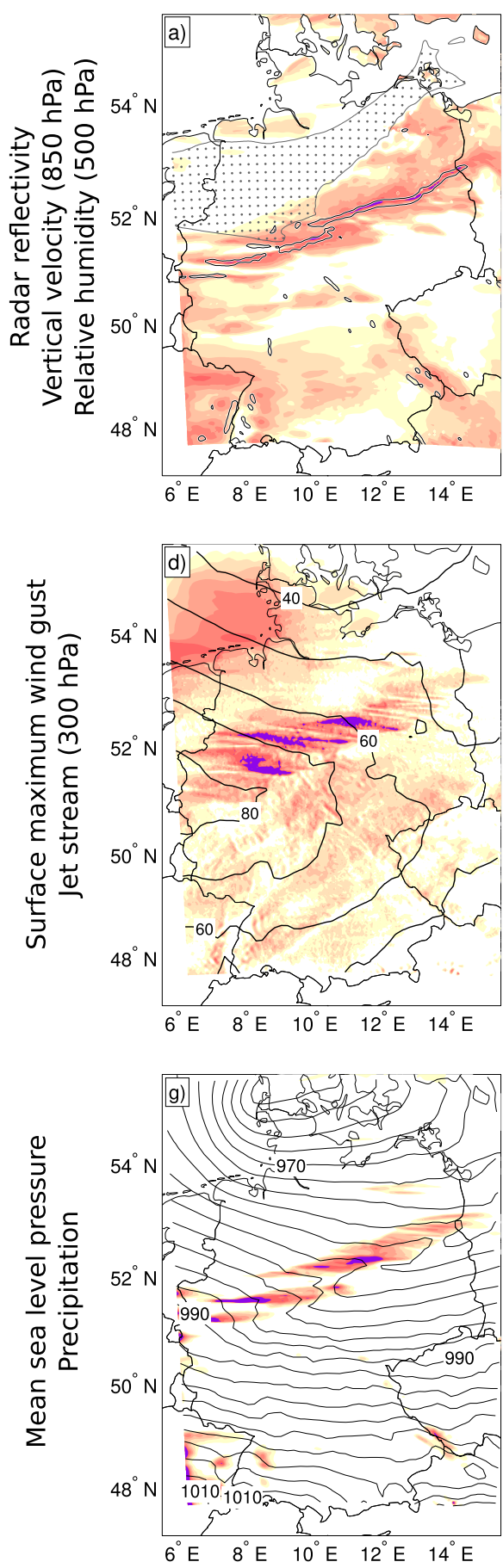

1800 UTC 18 January
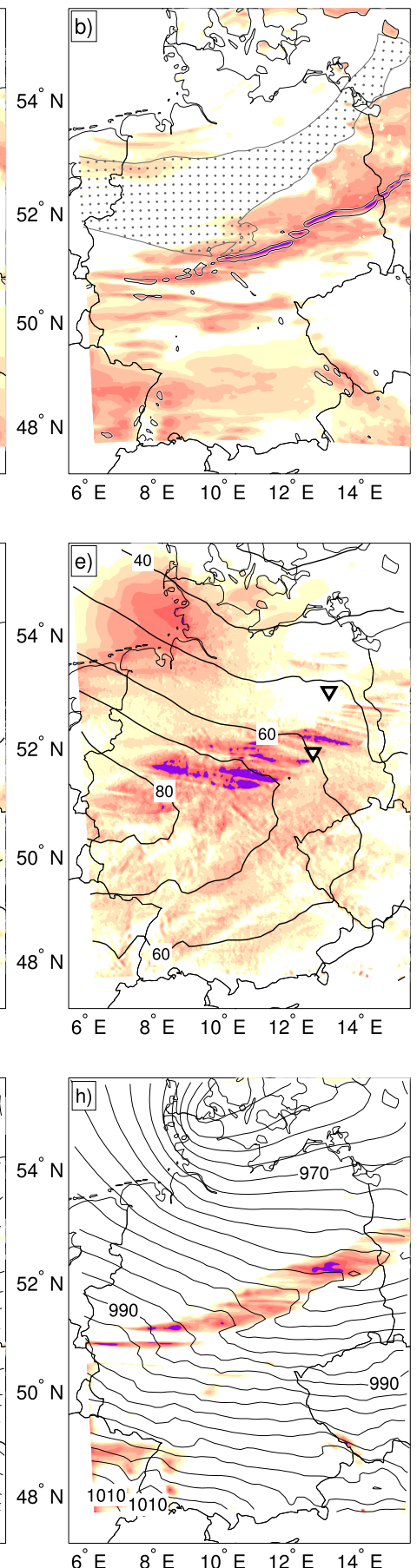

1900 UTC 18 January
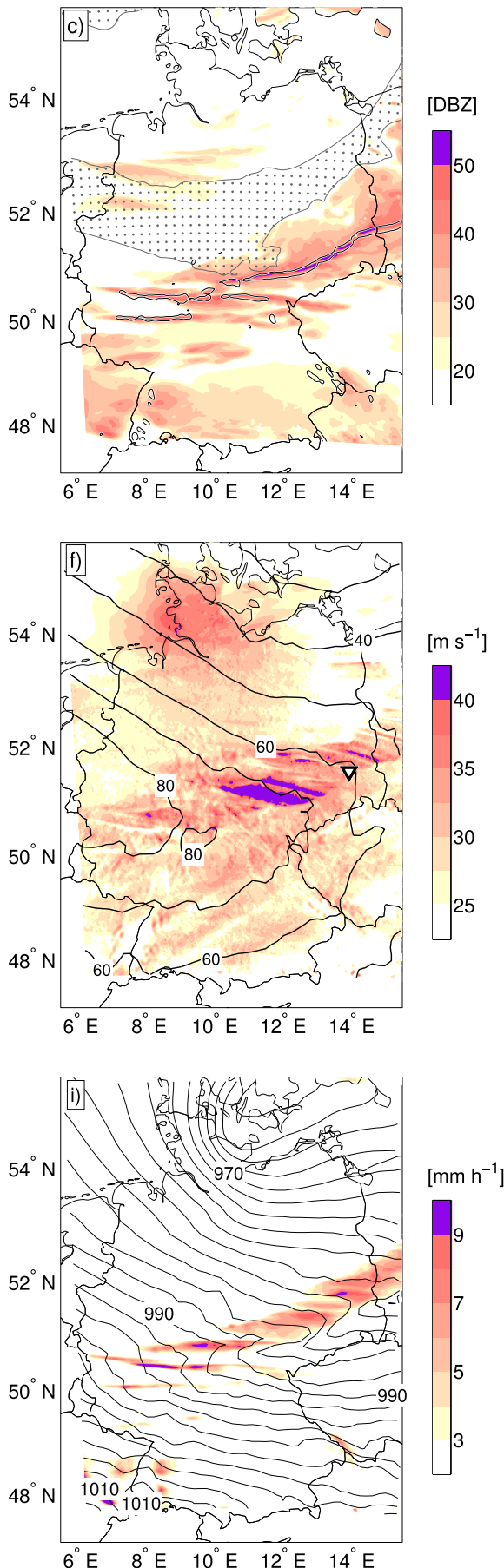

FIG. 8. Convection-permitting CCLM simulation (2.8-km grid spacing) of the cold front over Germany between 1700 and 1900 UTC 18 Jan. (a)-(c) Simulated radar reflectivity [shaded (dBZ)], upward vertical velocity at $850 \mathrm{hPa}$ (bold black line for velocity $>0.75 \mathrm{~m} \mathrm{~s}{ }^{-1}$ ), and relative humidity at $500 \mathrm{hPa}$ (region with relative humidity $<30 \%$ stippled). (d)-(f) Maximum $v_{\mathrm{DWD}}$ wind gust (shaded) and upper-level jet stream (contour lines each $10 \mathrm{~m} \mathrm{~s}^{-1}$ above $30 \mathrm{~m} \mathrm{~s}^{-1}$ ). Inverted triangles in (e) and (f) mark the positions of three verified tornado reports (see text for more details). (g)-(i) Hourly averaged precipitation rate (preceding hour) $\left(\mathrm{mm} \mathrm{h}^{-1}\right.$ ) (shaded) and mean sea level pressure $(\mathrm{hPa})$ (isobars each $2 \mathrm{hPa}$ ). 

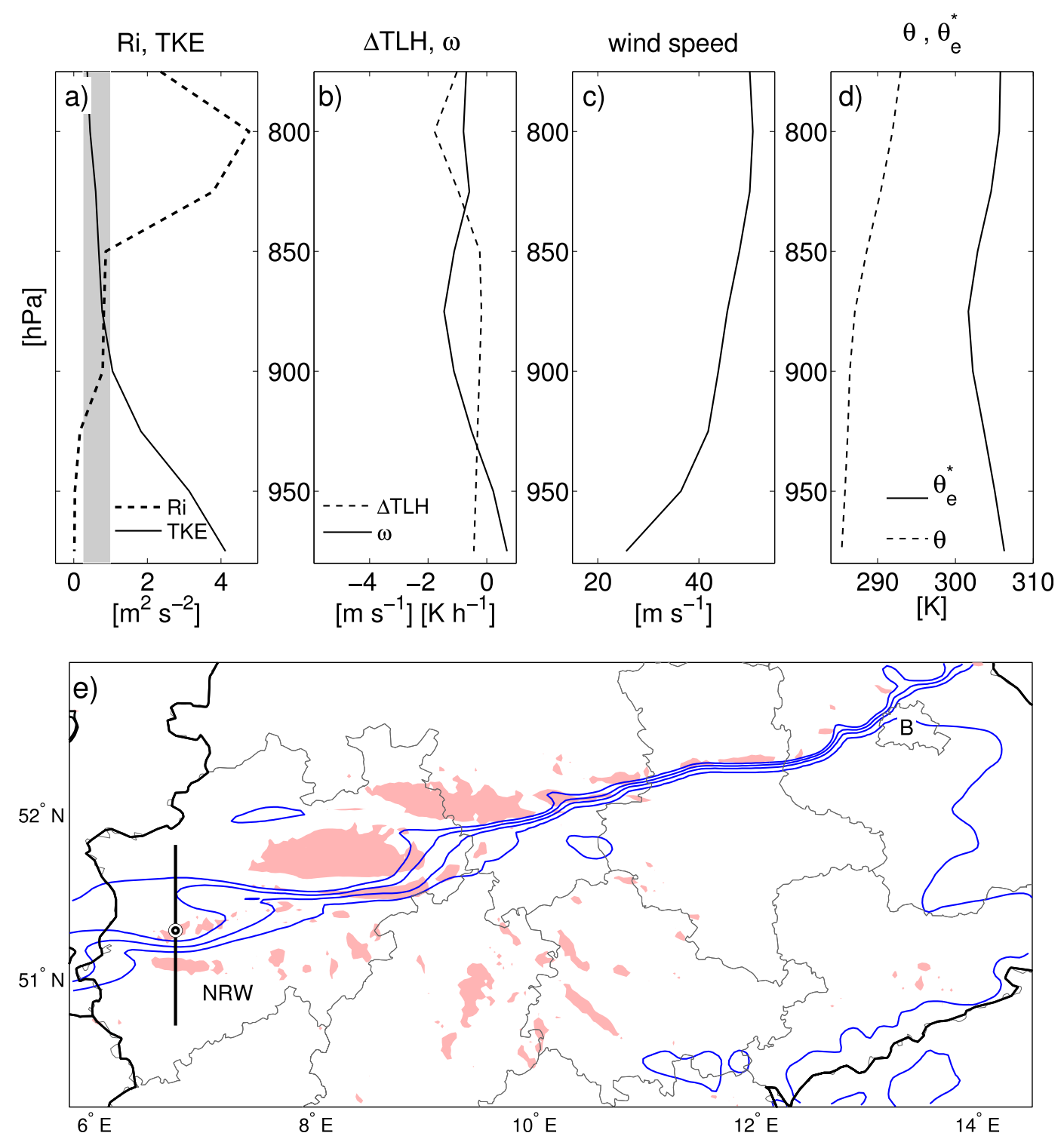

FIG. 9. Vertical profiles at $51.28^{\circ} \mathrm{N}, 6.76^{\circ} \mathrm{E}$ and at 1645 UTC 18 Jan. (a) Gradient Richardson number [Ri, dimensionless: shaded area (gray) marks the transition between stable $(\mathrm{Ri}>1)$ and turbulent flow $(\mathrm{Ri}<0.25)]$ and turbulent kinetic energy [TKE $\left.\left(\mathrm{m}^{2} \mathrm{~s}^{-2}\right)\right]$. (b) Vertical velocity $\left[\omega\left(\mathrm{m} \mathrm{s}^{-1}\right)\right]$ and diabatic heating rate $\left[\Delta \mathrm{TLH}\left(\mathrm{K} \mathrm{h}^{-1}\right)\right]$. (c) Magnitude of horizontal wind speed $\left(\mathrm{m} \mathrm{s}^{-1}\right)$. (d) Potential and equivalent potential temperature of saturated air $\left[\theta, \theta_{e}^{*}(\mathrm{~K})\right]$. (e) Areas over central Germany [including federal state borders; North Rhine-Westphalia (NRW); Berlin (B)] with instantaneous gust wind speed at 1645 UTC exceeding $32.7 \mathrm{~m} \mathrm{~s}^{-1}$ marked in red. Equivalent potential temperature $\left(\theta_{e}\right)$ along the front region at $950 \mathrm{hPa}$ marked with blue contours (lines between 300 and $306 \mathrm{~K}$ with interval of $2 \mathrm{~K}$ ) with higher values to the south. Black/white circles mark the locations of vertical profiles. The front normal cross section depicted in Fig. 11a is marked by a bold black line.

values of the gradient Richardson number below $850 \mathrm{hPa}$ and maximum values of TKE below $900 \mathrm{hPa}$ [TKE profiles before and afterward ( \pm 30 and $60 \mathrm{~min})$ show less TKE near the ground, not shown] imply that the boundary layer flow is turbulent (Fig. 9a). This lower-tropospheric region is generally associated with subsiding of air (Fig. 9b). Slightly negative values of the temperature difference due to latent heating reveal only a weak impact of evaporative cooling at this grid point (Fig. 9b). The vertical profile of horizontal wind speed shows boundary layer winds exceeding $45 \mathrm{~m} \mathrm{~s}^{-1}$ above about $850 \mathrm{hPa}$ (Fig. 9c). Based on vertical profiles of $\theta$ and $\theta_{e}^{*}$ (equivalent potential temperature of saturated air), the lower troposphere exhibits weak dry static 

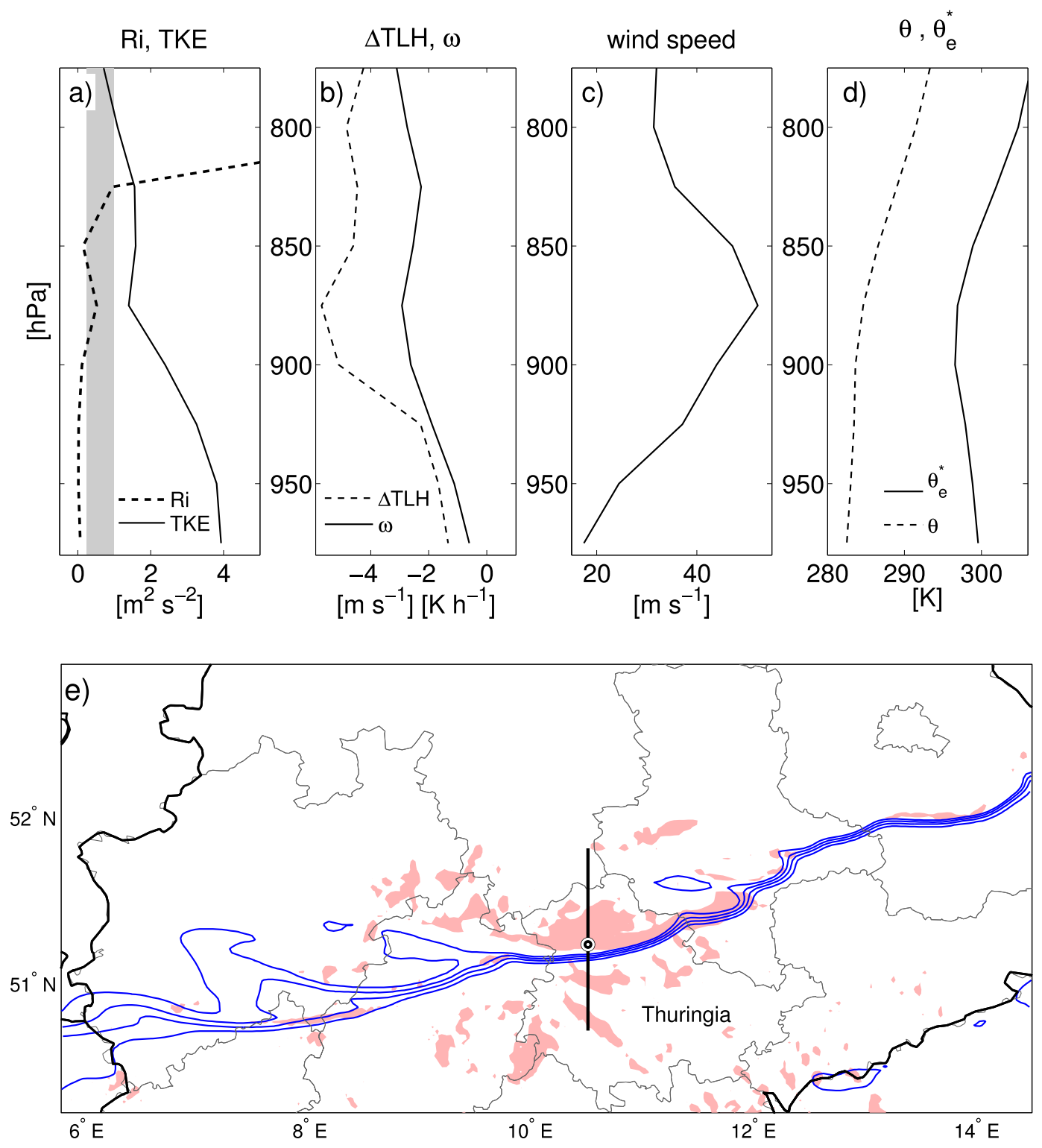

FIG. 10. As in Fig. 9, but for $51.28^{\circ} \mathrm{N}, 10.50^{\circ} \mathrm{E}$ at 1800 UTC $18 \mathrm{Jan}$ and the front normal cross section depicted in

Fig. $11 \mathrm{~b}$ is marked by a bold black line.

stability but conditional instability $\left(d \theta_{e}^{*} / d z<0\right)$ between the surface and $875 \mathrm{hPa}$ (Fig. 9d). Thus, favorable environmental conditions for mixing high momentum from higher layers down to the surface exist. A southnorth-orientated cross section normal to the cold front clearly shows the cross-frontal circulation (Fig. 11a). At low levels, strong convergence dominates leading to ascending motions above the surface cold front (surface cold front marked by sharp horizontal gradient of $\theta_{e}$ sloping upward and northward above $875 \mathrm{hPa}$ ). The upward motion in the frontal region is limited to below the $650-\mathrm{hPa}$ level. The layer below $900 \mathrm{hPa}$ is entirely turbulent ahead and behind the cold front $(\mathrm{Ri}<0.25)$. Thus, a combination of broadly subsiding motion and high values of horizontal momentum (wind speeds exceed $45 \mathrm{~m} \mathrm{~s}^{-1}$ at $900 \mathrm{hPa}$ ) is suggested to account for the severe surface wind gusts also ahead (south) of the cold front (Fig. 9e).

Conditions at 1800 UTC (Fig. 10) are somewhat similar to those at 1645 UTC although the cold front has intensified, as indicated by a sharpened $\theta_{e}$ gradient (Fig. 10e). Severe wind gusts are mainly concentrated to northern parts of Thuringia, Germany. Vertical profiles of TKE and $\mathrm{Ri}$ at $51.28^{\circ} \mathrm{N}, 10.5^{\circ} \mathrm{E}$ (where simulated 

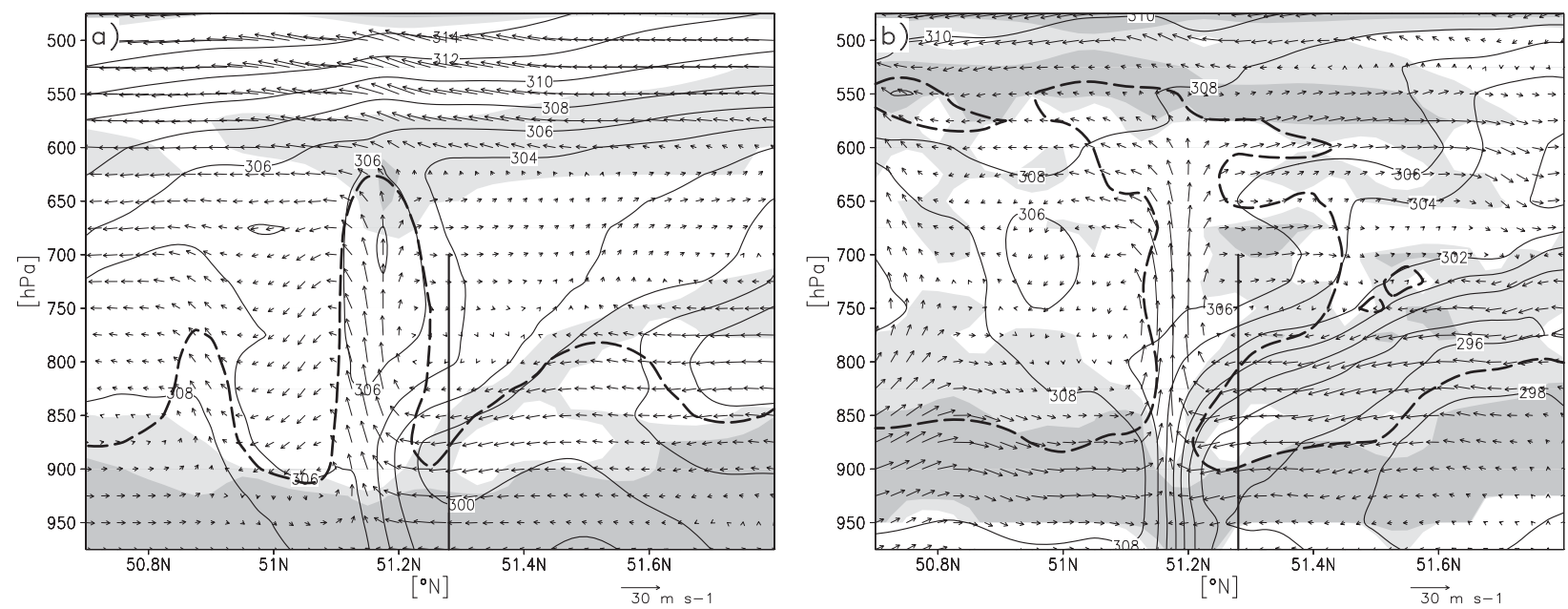

FIG. 11. Front normal cross sections for (a) 1645 UTC 18 Jan and (b) 1800 UTC 18 Jan. Locations of cross sections are marked by the bold black lines in Figs. $9 \mathrm{e}$ and 10e, respectively. Depicted are equivalent potential temperature $\left[\theta_{e}(\mathrm{~K})\right.$, solid lines], wind vectors of front normal and vertical wind component (scale shown at the lower-right corner, vertical velocity scaled by factor 10 for better representation), and magnitude of horizontal wind speed (above dashed line wind speeds exceed $45 \mathrm{~m} \mathrm{~s}^{-1}$ ). Gradient Richardson numbers (Ri) below 0.25 (turbulent flow) are shaded in dark gray. Regions with $0.25<\mathrm{Ri}<1$ (transition between stable and turbulent flow) are shaded in light gray. Bold vertical lines up to $700 \mathrm{hPa}$ at $51.28^{\circ} \mathrm{N}$ mark the locations of corresponding vertical profiles in Figs. 9 and 10.

surface wind gusts reach $36.0 \mathrm{~m} \mathrm{~s}^{-1}$ ) provide evidence that the flow is turbulent up to $825 \mathrm{hPa}$ (Fig. 10a) and is associated with enhanced subsiding motion, being strongest at $875 \mathrm{hPa}$ (Fig. 10b). The main contrast to the environmental conditions at the earlier time (discussed previously) is a strong increase in evaporative cooling and associated increased subsidence at lower-tropospheric levels; this contributes to the downward mixing of high momentum toward the ground, producing strong surface wind gusts. At the same time, the vertical profile of the horizontal wind exhibits maximum wind speeds exceeding $50 \mathrm{~m} \mathrm{~s}^{-1}$ at $875 \mathrm{hPa}$ (Fig. 10c). As previously, the lower troposphere indicates weak dry static stability but conditional instability (Fig. 10d). A comparison of simulated profiles with radiosonde profiles at 1800 UTC at Lindenberg, Germany (WMO 10393), reveals that the simulated stabilities are reliable (not shown). The vertical cross section (Fig. 11b) confirms the intensification of the cold front. The $\theta_{e}$ gradient has increased considerably and there is deep vertical ascent up to at least $600 \mathrm{hPa}$. Again, the ascent is favored by low-level convergence and upper-level divergence of the front normal wind component. The thickness of the turbulent flow layer has increased, reaching up to about $850 \mathrm{hPa}$. The transition layer of stable to turbulent flow partly extends up to $750 \mathrm{hPa}$. To summarize, conditions are favorable to produce strong surface wind gusts by mixing down existing high momentum within a turbulent and conditionally unstable environment. Additional analyses of large-scale environmental parameters like convective available potential energy, storm relative helicity, and vertical wind shear at 1800 UTC (not shown) revealed that the potential for convective severe weather was given (e.g., Romero et al. 2007).

Since the physical mechanisms leading to strong wind gusts were analyzed at only two specific grid points and times (see above), the representation of area-wide simulated wind gusts is now considered. The maximum simulated gust from two wind gust estimation methods $\left(v_{\mathrm{DWD}}, v_{\mathrm{TKE}}\right)$ for the whole simulated period (1200 UTC 18 January-0600 UTC 19 January) at each grid point of the convection-permitting simulation is compared to the maximum observed gust at stations for the same period (Fig. 12). While the patterns for both methods are quite similar, the maximum $v_{\text {TKE }}$ gusts (Fig. 12b) are consistently weaker than the maximum $v_{\text {DWD }}$ gusts (Fig. 12a). Compared to the maximum observed gust, $v_{\mathrm{DWD}}$ is overestimating gusts in both coastal and interior regions. In contrast, results of $v_{\text {TKE }}$ especially at coastal regions match observations with considerable skill. Additionally, both methods underestimate gusts at mountain peaks [e.g., at Brocken $\left.\left(51.8^{\circ} \mathrm{N}, 10.62^{\circ} \mathrm{E}, 1141 \mathrm{MSL}\right)\right]$. A comparison with insurance losses for winter storm Kyrill [cf. Fig. 6 in Donat et al. (2011)] indicates that regions with strong wind gusts and high losses are in good accordance. Although both wind gusts estimation methods have been developed and tested for coarse grid spacing, it is shown that both methods are suitable also for convection-permitting simulations. To conclude, the two different wind gust estimates are able to provide realistic area-wide and temporal wind gust distributions for windstorm Kyrill and provide evidence that strong 

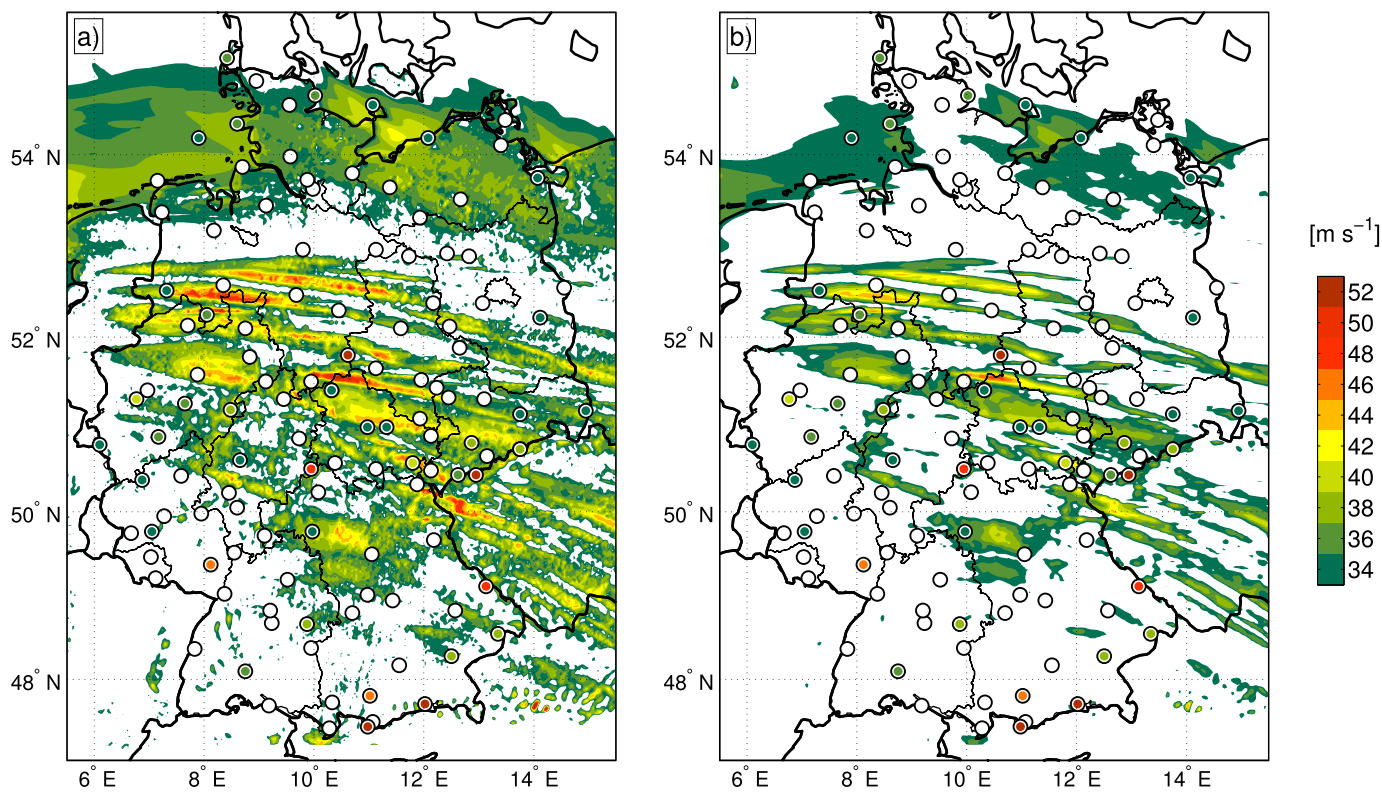

FIG. 12. Comparison of simulated (2.8-km grid-spacing simulation, shaded areas) and observed (colored points) 10-m wind gusts (both averaged between 1200 UTC 18 Jan and 0600 UTC 19 Jan) for (a) $v_{\text {DWD }}$ and (b) for $v_{\text {TKE. }}$ Federal state borders of Germany are included.

wind gusts occurred over a large area in Germany and nearby countries during the afternoon of 18 January 2007.

\section{Summary and discussion}

The formation of a secondary cyclone along the occluded front and strong wind gusts associated with severe winter storm Kyrill (January 2007) are examined using (high resolution) regional model simulations with COSMO-CLM. The objectives addressed in this study are (i) to document the kinematic environment and dynamical forcing leading to the uncommon formation of the secondary cyclone Kyrill II along the occluded front of parent low Kyrill I, (ii) to quantify the influence of diabatic processes on the intensity of Kyrill II, and (iii) to characterize the boundary layer conditions to determine the cause of the strong wind gusts along the cold front over Germany. Kyrill underwent explosive cyclogenesis over the North Atlantic Ocean as it crossed the strong upper-tropospheric jet stream. The formation of the secondary low Kyrill II, which moved farther toward continental Europe, led to serious socioeconomic impacts over large parts of central and eastern Europe (Fink et al. 2009). A split upper-level jet structure with accompanied upper-level divergence supported the maintenance of Kyrill II during its eastward movement. The importance of a split jet structure to cyclone development and maintenance has already been ascertained for recent windstorms such as Lothar (1999), Klaus (2009), and Xynthia (2010) (Wernli et al. 2002; Fink et al. 2012; Ludwig et al. 2014). While existing studies of secondary cyclogenesis along trailing fronts of a parent cyclone are limited mainly to cyclogenesis along warm and cold fronts (e.g., Rivals et al. 1998; Thorncroft and Hoskins 1990), Kyrill II evolves along the occluded front of mature cyclone Kyrill I. This type of secondary cyclogenesis is apparently a very rare event but has been mentioned by Neiman et al. (1993). Nevertheless, the mechanisms leading to the formation of Kyrill II are comparable with other cases of frontal cyclogenesis (Parker 1998a; Dacre and Gray 2006). A narrow band with high-PV values aligned along the occluded front exists at lower levels. If stretching deformation along the front is above a critical threshold, the deformation flow will sharpen the front. However, if the stretching deformation is reduced or negative, the PV strip is able to break up into multiple PV anomalies with corresponding cyclonic circulations. Consequently, the circulations extend toward the surface and are able to form waves along the front [cf. Dacre and Gray (2006), their Fig. 1]. In the case of Kyrill II, the alongfront stretching deformation (Renfrew et al. 1997) along the occluded front exhibits negative values and thus, together with a frontolytic environment, promotes the breakup of the PV band at 0000 UTC 18 January (cf. Fig. 4c) when Kyrill II forms. Also, strong diabatic heating rates exist, leading to increased diabatic PV modification near the point 
where Kyrill II evolves. Merging with the upper-level dry intrusion, which exhibits high values of PV, a PV tower formed across the depth of the troposphere and was enhanced during the ongoing development (Fig. 5d). The importance of diabatic heat release and the accompanying formation of a vertical extended PV tower during cyclone development have been described in several studies (e.g., Rossa et al. 2000; Wernli et al. 2002; Čampa and Wernli 2012; Ludwig et al. 2014). Sensitivity studies with reduced latent heat release within the convection parameterization scheme reveal the importance of diabatic forcing during the formation of Kyrill II. With reduced latent heat release, the development of Kyrill II is retarded, leading to a less intense cyclone over central Europe. However, the fact that a secondary cyclone still developed implies that other factors (e.g., forcing from the split uppertropospheric jet stream) also contributed to the secondary development; the quantification of this uppertropospheric forcing is left for further research. To summarize, the realistic simulation of the uncommon secondary cyclogenesis of windstorm Kyrill with COSMO-CLM provides new insights into crucial (thermo) dynamical aspects of the formation of Kyrill II along the occluded front of the mature cyclone Kyrill I.

The convection-permitting simulation $(2.8-\mathrm{km}$ grid spacing) of Kyrill II's cold front provides insight into dynamical aspects of the severe wind gusts along the front. The simulation reproduces realistic features observed during the passage over Germany [e.g., the simulated lines of maximum radar echoes; cf. Fig. 5 in Fink et al. (2009)]. The simulated gusts along the cold front often exceed hurricane-force wind speeds, as observed. The location of the observed tornadoes, below the left exit region of the upper-tropospheric jet stream, is known to be favorable for severe weather (Rose et al. 2004). The vertical state of the lower atmosphere during the passage of the cold front was analyzed at two grid points to determine the physical mechanisms causing the wind gusts. While the boundary layer shows weak dry static stability $(d \theta / d z \geq 0)$, the vertical gradient of $\theta_{e}^{*}$ implies that the troposphere below $875 \mathrm{hPa}$ is conditionally unstable $\left(d \theta_{e}^{*} / d z<0\right)$. Also, the small values of gradient Richardson number and maximum values of TKE near the ground characterize the boundary layer flow to be turbulent. The consideration of the diabatic heating rates implies that evaporative cooling occurs together within the downward motions contributing to the amplification of surface wind gusts. Thus, the strong gusts are embedded in a weak statically stable, conditionally unstable, and turbulent environment where it is feasible that high momentum (wind speeds above $850 \mathrm{hPa}$ exceed $45 \mathrm{~m} \mathrm{~s}^{-1}$ ) is mixed downward toward the surface. Although strong wind conditions are generally associated with weak static stability, the prevalence of conditional instability in cases similar to the current situation is not known and thus might be an avenue for further research.

The realistic representation of the physical mechanism causing strong wind gusts by the COSMO-CLM permits the area-wide assessment of wind gusts at high temporal coverage. The realistic representation of wind gusts during windstorm events at high resolution (here calculated using two different wind gust estimation approaches) is of particular interest for a range of impact studies (e.g., forest and private household losses) and to enhance the predictability of such events. For storm Kyrill there is evidence of widespread strong wind gusts during the passage of the cold front over Germany and nearby countries, both from wind gust measurements and resulting insurance losses [cf. Fig. 6 in Donat et al. (2011)].

The present study provides evidence of the anomalous characteristics of storm Kyrill, including the secondary development along the occluded front and the severe cold front over central Europe, both quite uncommon occurrences according to the current literature. Future work could focus on the analysis of similar storms [e.g., winter storm Emma in March 2008 for another coldseason derecho, cf. Gatzen et al. (2011)] to identify how rare such developments actually are and potentially to enhance their predictability.

Acknowledgments. We thank the European Centre for Medium-Range Weather Forecasts (ECMWF, United Kingdom) for providing the ERA-Interim data and the German Weather Service (DWD) for providing synoptic station data. We thank the German Climate Computer Centre (DKRZ, Hamburg) for computer and storage resources within the context of DKRZ project ANDIVA (Number 105). We thank Helen Dacre and John Methven (both at the University of Reading) for discussions. We thank the editor, David Schultz, and four anonymous reviewers for their constructive comments on an earlier version of the manuscript.

\section{REFERENCES}

Ayrault, F., F. Lalaurette, A. Joly, and C. Loo, 1995: North Atlantic ultra high frequency variability: An introductory survey. Tellus, 47A, 671-696, doi:10.1034/j.1600-0870.1995.00112.x.

Baldauf, M., A. Seifert, J. Förstner, D. Majewski, M. Raschendorfer, and T. Reinhardt, 2011: Operational convective-scale numerical weather prediction with the COSMO Model: Description and sensitivities. Mon. Wea. Rev., 139, 3887-3905, doi:10.1175/ MWR-D-10-05013.1.

Bishop, C. H., 1996: Domain-independent attribution. Part I: Reconstructing the wind from estimates of vorticity and 
divergence using free space Green's functions. J. Atmos. Sci., 53, 241-252, doi:10.1175/1520-0469(1996)053<0241: DIAPIR $>2.0 . \mathrm{CO} ; 2$.

— , and A. J. Thorpe, 1994a: Frontal wave stability during moist deformation frontogenesis. Part I: Linear wave dynamics. J. Atmos. Sci., 51, 852-873, doi:10.1175/1520-0469(1994)051<0852: FWSDMD $>2.0 . \mathrm{CO} ; 2$.

$\longrightarrow$, and — 1994b: Frontal wave stability during moist deformation frontogenesis. Part II: The suppression of nonlinear wave development. J. Atmos. Sci., 51, 874-888, doi:10.1175/ 1520-0469(1994)051<0874:FWSDMD>2.0.CO;2.

Born, K., P. Ludwig, and J. G. Pinto, 2012: Wind gust estimation for mid-European winter storms: Towards a probabilistic view. Tellus, 64A, 17471, doi:10.3402/tellusa.v64i0.17471.

Brasseur, O., 2001: Development and application of a physical approach to estimating wind gusts. Mon. Wea. Rev., 129, 5-25, doi:10.1175/1520-0493(2001)129<0005:DAAOAP>2.0.CO;2.

Browning, K. A., 1997: The dry intrusion perspective of extratropical cyclone development. Meteor. Appl., 4, 317-324, doi:10.1017/S1350482797000613.

__ and R. Reynolds, 1994: Diagnostic study of a narrow coldfrontal rainband and severe winds associated with a stratospheric intrusion. Quart. J. Roy. Meteor. Soc., 120, 235-257, doi:10.1002/qj.49712051602.

__ and B. W. Golding, 1995: Mesoscale aspects of a dry intrusion within a vigorous cyclone. Quart. J. Roy. Meteor. Soc., 121, 463-493, doi:10.1002/qj.49712152302.

Campa, J., and H. Wernli, 2012: A PV perspective on the vertical structure of mature midlatitude cyclones in the Northern Hemisphere. J. Atmos. Sci., 69, 725-740, doi:10.1175/ JAS-D-11-050.1.

Carlson, T. N., 1991: Mid-latitude Weather Systems. Harper Collins, $507 \mathrm{pp}$.

Carrera, M. L., J. R. Gyakum, and D.-L. Zhang, 1999: A numerical case study of secondary marine cyclogenesis sensitivity to initial error and varying physical processes. Mon. Wea. Rev., 127, 641-660, doi:10.1175/1520-0493(1999)127<0641: ANCSOS $>2.0 . \mathrm{CO} ; 2$.

Chaboureau, J.-P., and A. J. Thorpe, 1999: Frontogenesis and the development of secondary wave cyclones in FASTEX. Quart. J. Roy. Meteor. Soc., 125, 925-940, doi:10.1002/ qj.49712555509.

Dacre, H. F., and S. L. Gray, 2006: Life-cycle simulations of shallow frontal waves and the impact of deformation strain. Quart. J. Roy. Meteor. Soc., 132, 2171-2190, doi:10.1256/qj.05.238.

— and _ 2013: Quantifying the climatological relationship between extratropical cyclone intensity and atmospheric precursors. Geophys. Res. Lett., 40, 2322-2327, doi:10.1002/ grl.50105.

Danard, M. B., 1964: On the influence of released latent heat on cyclone development. J. Appl. Meteor., 3, 27-37, doi:10.1175/ 1520-0450(1964)003<0027:OTIORL > 2.0.CO;2.

Dee, D. P., and Coauthors, 2011: The ERA-Interim reanalysis: Configuration and performance of the data assimilation system. Quart. J. Roy. Meteor. Soc., 137, 553-597, doi:10.1002/ qj.828.

De Rooy, W. C., and K. Kok, 2004: A combined physical statistical approach for the downscaling of model wind speed. Wea. Forecasting, 19, 485-495, doi:10.1175/1520-0434(2004)019<0485: ACPAFT $>2.0 . \mathrm{CO} ; 2$.

Dickinson, M. J., L. F. Bosart, W. E. Bracken, G. J. Hakim, D. M. Schultz, M. A. Bedrick, and K. R. Tyle, 1997: The March 1993 superstorm cyclogenesis: Incipient phase synoptic- and convective-scale flow interaction and model performance. Mon. Wea. Rev., 125, 3041-3072, doi:10.1175/ 1520-0493(1997)125<3041:TMSCIP>2.0.CO;2.

Doms, G., and Coauthors, 2011: A description of the nonhydrostatic regional model LM. Part II: Physical parameterization. Tech. Rep., Consortium for Small-Scale Modelling, $161 \mathrm{pp}$. [Available online at http://www.cosmo-model.org.]

Donat, M. G., T. Pardowitz, G. C. Leckebusch, U. Ulbrich, and O. Burghoff, 2011: High-resolution refinement of a storm loss model and estimation of return periods of loss-intensive storms over Germany. Nat. Hazards Earth Syst. Sci., 11, 2821-2833, doi:10.5194/nhess-11-2821-2011.

Dotzek, N., P. Groenemeijer, B. Feuerstein, and A. M. Holzer, 2009: Overview of ESSL's severe convective storms research using the European Severe Weather Database ESWD. Atmos. Res., 93, 575-586, doi:10.1016/j.atmosres.2008.10.020.

Doyle, J. D., C. Amerault, C. A. Reynolds, and P. A. Reinecke, 2014: Initial condition sensitivity and predictability of a severe extratropical cyclone using a moist adjoint. Mon. Wea. Rev., 142, 320-342, doi:10.1175/MWR-D-13-00201.1.

Dritschel, D. G., P. H. Haynes, M. N. Juckes, and T. G. Shepherd, 1991: The stability of a two-dimensional vorticity filament under uniform strain. J. Fluid Mech., 230, 647-665, doi:10.1017/S0022112091000915.

Durst, C. D., 1960: Wind speeds over short periods of time. Meteor. Mag., 89, 181-186.

Fink, A. H., T. Brücher, V. Ermert, A. Krüger, and J. G. Pinto, 2009: The European storm Kyrill in January 2007: Synoptic evolution, meteorological impacts and some considerations with respect to climate change. Nat. Hazards Earth Syst. Sci., 9, 405-423, doi:10.5194/nhess-9-405-2009.

_ S. Pohle, J. G. Pinto, and P. Knippertz, 2012: Diagnosing the influence of diabatic processes on the explosive deepening of extratropical cyclones. Geophys. Res. Lett., 39, L07803, doi:10.1029/2012GL051025.

Friederichs, P., M. Goeber, S. Bentzien, A. Lenz, and R. Krampitz, 2009: A probabilistic analysis of wind gusts using extreme value statistics. Meteor. Z., 18, 615-629, doi:10.1127/ 0941-2948/2009/0413.

Gall, R., 1976: The effects of released latent heat in growing baroclinic waves. J. Atmos. Sci., 33, 1686-1701, doi:10.1175/ 1520-0469(1976)033<1686:TEORLH>2.0.CO;2.

Gatzen, C., P. Púčik, and D. Ryva, 2011: Two cold-season derechoes in Europe. Atmos. Res., 100, 740-748, doi:10.1016/ j.atmosres.2010.11.015.

Goyette, S., O. Brasseur, and M. Beniston, 2003: Application of a new wind gust parameterisation: Multiple scale studies performed with the Canadian regional climate model. J. Geophys. Res., 108, 4374, doi:10.1029/2002JD002646.

Gray, S. L., and H. F. Dacre, 2006: Classifying dynamical forcing mechanisms using a climatology of extratropical cyclones. Quart. J. Roy. Meteor. Soc., 132, 1119-1137, doi:10.1256/ qj.05.69.

Hoskins, B. J., and P. J. Valdes, 1990: On the existence of storm-tracks. J. Atmos. Sci., 47, 1854-1864, doi:10.1175/ 1520-0469(1990)047<1854:OTEOST>2.0.CO;2.

—_, and K. I. Hodges, 2002: New perspectives on the Northern Hemisphere winter storm tracks. J. Atmos. Sci., 59, 10411061, doi:10.1175/1520-0469(2002)059<1041:NPOTNH >2.0. $\mathrm{CO} ; 2$.

Johns, R. H., and W. D. Hirt, 1987: Derechos: Widespread convectively induced windstorms. Wea. Forecasting, 2, 32-49, doi:10.1175/1520-0434(1987)002<0032:DWCIW>2.0.CO;2. 
Joos, H., and H. Wernli, 2012: Influence of microphysical processes on the potential vorticity development in a warm conveyor belt: A case-study with the limited-area model COSMO. Quart. J. Roy. Meteor. Soc., 138, 407-418, doi:10.1002/qj.934.

Keyser, D., M. J. Reeder, and R. J. Reed, 1988: A generalization of Petterssen's frontogenesis function and its relation to the forcing of vertical motion. Mon. Wea. Rev., 116, 762-781, doi:10.1175/1520-0493(1988)116<0762:AGOPFF>2.0.CO;2.

Ludwig, P., J. G. Pinto, M. Reyers, and S. L. Gray, 2014: The role of anomalous SST and surface fluxes over the southeastern North Atlantic in the explosive development of windstorm Xynthia Quart. J. Roy. Meteor. Soc., 140, 1729-1741, doi:10.1002/qj.2253.

Mailier, P. J., D. B. Stephenson, C. A. T. Ferro, and K. I. Hodges, 2006: Serial clustering of extratropical cyclones. Mon. Wea Rev., 134, 2224-2240, doi:10.1175/MWR3160.1.

Martin, J. E., 2006: Mid-Latitude Atmospheric Dynamics-A First Course. Wiley, 324 pp.

Mellor, G., and T. Yamada, 1982: Development of a turbulence closure model for geophysical fluid problems. Rev. Geophys. Space Phys., 20, 851-875, doi:10.1029/RG020i004p00851.

Moore, J. T., and G. E. Vanknowe, 1992: The effect of jet-streak curvature on kinematic fields. Mon. Wea. Rev., 120, 2429-2441, doi:10.1175/1520-0493(1992)120<2429:TEOJSC > 2.0.CO;2.

Neiman, P. J., M. A. Shapiro, and L. S. Fedor, 1993: The life cycle of an extratropical marine cyclone. Part II: Mesoscale structure and diagnostics. Mon. Wea. Rev., 121, 2177-2199, doi:10.1175/ 1520-0493(1993)121<2177:TLCOAE > 2.0.CO;2.

Palmen, E., and C. W. Newton, 1969: Atmospheric Circulation Systems: Their Structure and Physical Interpretation. Academic Press, 603 pp.

Panofsky, H. A., and J. A. Dutton, 1984: Atmospheric Turbulence: Models and Methods for Engineering Applications. John Wiley \& Sons, $397 \mathrm{pp}$.

Parker, D. J., 1998a: Secondary frontal waves in the North Atlantic region: A dynamical perspective of current ideas. Quart. J. Roy. Meteor. Soc., 124, 829-856, doi:10.1002/qj.49712454709.

_ 1998b: Barotropic instability in frontolytic strain. Quart. J. Roy. Meteor. Soc., 124, 1617-1632, doi:10.1002/qj.49712454913.

Petterssen, S., 1936: Contribution to the theory of frontogenesis. Geofys. Publ., 11, 1-27. [Available online at ftp://ftp.uib.no/pub/gfi/ ngftf/Geofysiske\%20Publikasjoner/11/NGF_GP_Vol11_no6.pdf.]

Pinto, J. G., N. Bellenbaum, M. K. Karremann, and P. M. DellaMarta, 2013: Serial clustering of extratropical cyclones over the North Atlantic and Europe under recent and future climate conditions. J. Geophys. Res. Atmos., 118, 12 476-12 485, doi:10.1002/2013JD020564

Renfrew, I. A., A. J. Thorpe, and C. H. Bishop, 1997: The role of the environmental flow in the development of secondary frontal cyclones. Quart. J. Roy. Meteor. Soc., 123, 1653-1675, doi:10.1002/qj.49712354210.

Ritter, B., and J. F. Geleyn, 1992: A comprehensive radiation scheme for numerical weather prediction models with potential applications in climate simulations. Mon. Wea. Rev., 120,303-325, doi:10.1175/1520-0493(1992)120<0303:ACRSFN>2.0.CO;2.

Rivals, H., J.-P. Cammas, and I. A. Renfrew, 1998: Secondary cyclogenesis: The initiation phase of a frontal wave observed over the eastern Atlantic. Quart. J. Roy. Meteor. Soc., 124, 243-267, doi:10.1002/qj.49712454511.
Rockel, B., A. Will, and A. Hense, Eds., 2008: The regional climate model COSMO-CLM (CCLM). Meteor. Z., 17, 347-348, doi:10.1127/0941-2948/2008/0309.

Romero, R., M. Gayà, and C. A. Doswell III, 2007: European climatology of severe convective storm environmental parameters: A test for significant tornado events. Atmos. Res., 83, 389404, doi:10.1016/j.atmosres.2005.06.011.

Rose, S. F., P. V. Hobbs, J. D. Locatelli, and M. T. Stoelinga, 2004: A 10-yr climatology relating the locations of reported tornadoes to the quadrants of upper-level jet streaks. Wea. Forecasting, 19, 301-309, doi:10.1175/1520-0434(2004)019<0301: AYCRTL $>2.0 . C O ; 2$.

Rossa, A. M., H. Wernli, and H. C. Davies, 2000: Growth and decay of an extra-tropical cyclone's PV-tower. Meteor. Atmos. Phys., 73, 139-156, doi:10.1007/s007030050070.

Sanders, F., and J. R. Gyakum, 1980: Synoptic-dynamic climatology of the "bomb." Mon. Wea. Rev., 108, 1589-1606, doi:10.1175/ 1520-0493(1980)108<1589:SDCOT>2.0.CO;2.

Schrage, J. M., and A. H. Fink, 2012: Nocturnal continental lowlevel stratus over tropical West Africa: Observations and possible mechanisms controlling its onset. Mon. Wea. Rev., 140, 1794-1809, doi:10.1175/MWR-D-11-00172.1.

Schulz, J.-P., 2008: Revision of the turbulent gust diagnostics in the COSMO model. COSMO Newsl., 8, 17-22. [Available online at http://www.cosmo-model.org/content/model/documentation/ newsLetters/newsLetter08/cnl8_schulz.pdf.]

, and E. Heise, 2003: A new scheme for diagnosing near-surface convective gusts. COSMO Newsl., 3, 221-225. [Available online at http://www.cosmo-model.org/content/model/documentation/ newsLetters/newsLetter03/cnl3-chp9-15.pdf.]

Swiss Re, cited 2008: Natural catastrophes and man-made disasters in 2007: High losses in Europe. Sigma Rep. 1/2008. [Available online at www.swissre.com/sigma/.]

Thorncroft, C. D., and B. J. Hoskins, 1990: Frontal cyclogenesis. J. Atmos. Sci., 47, 2317-2336, doi:10.1175/1520-0469(1990)047<2317: $\mathrm{FC}>2.0 . \mathrm{CO} ; 2$

Tiedtke, M., 1989: A comprehensive mass flux scheme for cumulus parameterization in large-scale models. Mon. Wea. Rev., 117, 1779-1800, doi:10.1175/1520-0493(1989)117<1779: ACMFSF $>2.0 . \mathrm{CO} ; 2$.

Uccellini, L. W., and D. R. Johnson, 1979: The coupling of upper and lower tropospheric jet streaks and implications for the development of severe convective storms. Mon. Wea. Rev., 107, 682-703, doi:10.1175/1520-0493(1979)107<0682: TCOUAL $>2.0 . C O ; 2$.

Wanner, H., S. Bronnimann, C. Casty, D. Gyalistras, J. Luterbacher, C. Schmutz, D. B. Stephenson, and E. Xoplaki, 2001: North Atlantic oscillation: Concepts and studies. Surv. Geophys., 22, 321-382, doi:10.1023/A:1014217317898.

Wernli, H., S. Dirren, M. A. Liniger, and M. Zillig, 2002: Dynamical aspects of the life cycle of the winter storm 'Lothar' (24-26 December 1999). Quart. J. Roy. Meteor. Soc., 128, 405-429, doi:10.1256/003590002321042036.

Wieringa, J., 1973: Gust factors over open water and built up country. Bound.-Layer Meteor., 3, 424-441, doi:10.1007/BF01034986.

Young, M. V., G. A. Monk, and K. A. Browning, 1987: Interpretation of satellite imagery of a rapidly deepening cyclone. Quart. J. Roy. Meteor. Soc., 113, 1089-1115, doi:10.1002/qj.49711347803. 